\section{A) Check for updates}

Cite this: Nanoscale, 2020, 12, 12196

\title{
Recent advances in engineering active sites for photocatalytic $\mathrm{CO}_{2}$ reduction
}

\begin{abstract}
Yanan Bo, Chao Gao (D) * and Yujie Xiong (D)*
The photocatalytic conversion of green-house gas $\mathrm{CO}_{2}$ into high value-added carbonaceous fuels and chemicals through harvesting solar energy is a great promising strategy for simultaneously tackling global environmental issues and the energy crisis. Considering the vital role of active sites in determining the activity and selectivity in photocatalytic $\mathrm{CO}_{2}$ reduction reactions, great efforts have been directed toward engineering active sites for fabricating efficient photocatalysts. This review highlights recent advances in the strategies for engineering active sites on surfaces and in open frameworks toward photocatalytic $\mathrm{CO}_{2}$ reduction, referring to surface vacancies, doped heteroatoms, functional groups, loaded metal nanoparticles, crystal facets, heterogeneous/homogeneous single-site catalysts and metal nodes/organic

linkers in metal organic frameworks.
\end{abstract}

Received 1st April 2020,

Accepted 11th May 2020

DOI: $10.1039 / \mathrm{d} 0 \mathrm{nr} 02596 \mathrm{~h}$

rsc.li/nanoscale

\section{Introduction}

With increasing energy demand and extensive emission of green-house gases, it becomes more critical to develop sustainable energy systems. ${ }^{1-3}$ One of the best solutions is to convert

Hefei National Laboratory for Physical Sciences at the Microscale, iChEM (Collaborative Innovation Center of Chemistry for Energy Materials), National Synchrotron Radiation Laboratory, and School of Chemistry and Materials Science, University of Science and Technology of China, Hefei, Anhui 230026, P. R. China. E-mail:yjxiong@ustc.edu.cn, gaoc@ustc.edu.cn

$\mathrm{CO}_{2}$ into high value-added carbonaceous fuels and chemical building blocks by means of solar energy. ${ }^{4}$ To realize such $\mathrm{CO}_{2}$ conversion practicably, there is an urgent need to develop highly efficient photocatalysts.

The capacity of photocatalysts to drive $\mathrm{CO}_{2}$ conversion largely depends on three crucial factors: (i) light harvesting; (ii) charge separation and transfer; (iii) surface reactions. Numerous studies have endeavored to improve light utilization, charge separation and transfer efficiency during the past decades. ${ }^{1,3}$ Beyond that, surface reactions referring to effective $\mathrm{CO}_{2}$ adsorption and activation play a critical role in enhancing

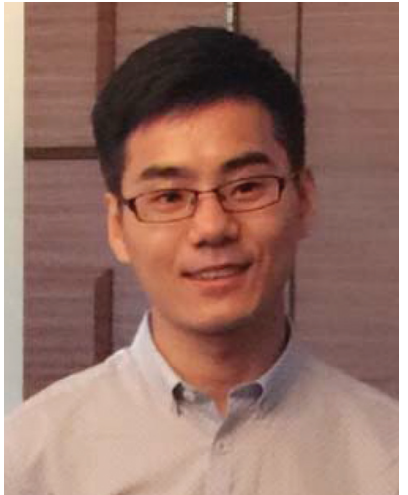

Chao Gao
Chao Gao received his B.S. in chemistry in 2010 from Anhui Normal University, and Ph.D. in inorganic chemistry in 2015 (with Professors Xingjiu Huang and Zhiyong Tang) from the University of Science and Technology of China (USTC). During his Ph.D. research, he had two-year training (2013-2015) with Professor Zhiyong Tang at the National Center for Nanoscience and Technology (NCNST). He is currently an Associate Professor at USTC. His current research interests are focused on the design and synthesis of photocatalysts and photoelectrodes for carbon dioxide reduction, nitrogen fixation and methane conversion. 
the performance for $\mathrm{CO}_{2}$ conversion. ${ }^{5,6}$ More specifically, the adsorption and activation of $\mathrm{CO}_{2}$ molecules exactly occur at the active sites on surfaces. As $\mathrm{CO}_{2}$ conversion involves multielectron reduction processes, various carbonaceous reduction products could be obtained, accompanied by competitive hydrogen evolution in the presence of water on account of its lower redox potential. ${ }^{7}$ In this regard, engineering the active sites is vital to regulate the reaction pathways through altering the adsorption behavior of intermediates and suppressing the undesired hydrogen evolution, achieving a high selectivity for specific reduction products. Moreover, in addition to affecting surface reactions, engineering the active sites can also influence the efficiencies of charge separation and light harvesting, both of which will influence the whole performance of photocatalytic $\mathrm{CO}_{2}$ reduction. Toward this end, great research efforts have been devoted to engineering active sites aiming at high activity and selectivity in photocatalytic $\mathrm{CO}_{2}$ reduction.

The photocatalytic system can be considered to consist of two parts: light absorbers and active sites. ${ }^{5}$ Generally, the light absorbers are semiconductors, quantum dots and organic photosensitizers, while the active sites exist on the surface or in the porous matrix of these light absorbers. ${ }^{1,6,8,9}$ The active sites can be engineered in the form of surface vacancies, ${ }^{10-12}$ doped heteroatoms, functional groups, ${ }^{13,14}$ loaded metal nanoparticles, crystal facets, heterogeneous single-site catalysts, ${ }^{15-17}$ homogeneous single-site catalysts ${ }^{18-23}$ and metal nodes/ organic linkers in metal-organic frameworks (MOFs), by which the coordinately unsaturated state, electronic structure, acidity/alkalinity, and local environment of the active sites can be adjusted for enhancing activity and selectivity in photocatalytic $\mathrm{CO}_{2}$ reduction.

Taken together, the advancements of photocatalytic $\mathrm{CO}_{2}$ reduction essentially profit from the development of well-

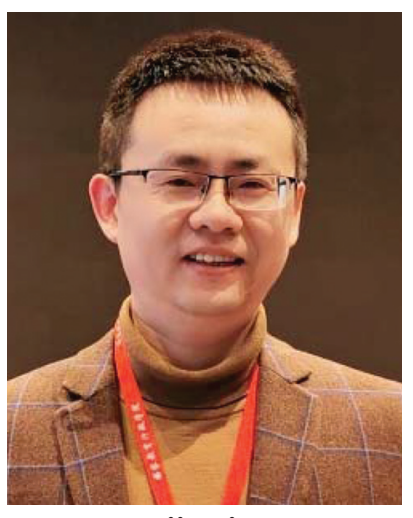

Yujie Xiong
Yujie Xiong received his B.S. in chemical physics in 2000 and Ph.D. in inorganic chemistry in 2004, both from the University of Science and Technology of China (USTC). From 2004 to 2009, he worked as a Postdoctoral Fellow at the University of Washington in Seattle and as a Research Associate at the University of Illinois at Urbana-Champaign. He was Principal Scientist of the National Nanotechnology Infrastructure Network (NSF-NNIN) site at Washington University in St. Louis between 2009 and 2011. He joined the USTC faculty in 2011, and currently is Chair Professor of Chemistry. His research interests include inorganic materials and devices for carbon dioxide reduction, nitrogen fixation, methane conversion, water splitting and chemical production. defined highly active sites in photocatalysts. In this review, we will focus on recent advances in rationally engineering active sites for photocatalytic $\mathrm{CO}_{2}$ reduction. Firstly, the basic principles of photocatalytic $\mathrm{CO}_{2}$ reduction will be briefly discussed based on the currently developed mechanisms, from which we can outline the critical parameters for engineering active sites. Secondly, the developed strategies for engineering active sites on surfaces and in open frameworks are systematically summarized, including creating surface vacancies, doping heteroatoms, modifying functional groups, loading metal nanoparticles, engineering crystal facets, dispersing heterogeneous single-site catalysts, anchoring homogeneous single-site catalysts and modulating metal nodes/organic linkers in MOFs. Finally, the existing challenges and future prospects are presented.

\section{Basic principles of photocatalytic $\mathrm{CO}_{2}$ reduction}

The photocatalytic reduction of $\mathrm{CO}_{2}$ into fuels with $\mathrm{H}_{2} \mathrm{O}$ driven by solar energy has drawn much attention since the investigation by Fujishima in $1979 .^{2}$ The overall process of photocatalytic $\mathrm{CO}_{2}$ reduction involves the following three critical steps (Fig. 1): (i) the photocatalyst absorbs the incident photons with an energy equal to or higher than the bandgap energy and generates electron-hole pairs; (ii) the photogenerated electron-hole pairs are then separated and electrons migrate to the active sites where the $\mathrm{CO}_{2}$ molecules are adsorbed; (iii) the photogenerated electrons are transferred to the adsorbed $\mathrm{CO}_{2}$ molecules and initiate $\mathrm{CO}_{2}$ reduction. Simultaneously, the photogenerated holes are consumed to oxidize $\mathrm{H}_{2} \mathrm{O}$ into $\mathrm{O}_{2}$. In the first step, the key to the full utilization of solar light is to absorb visible/infrared light, as natural

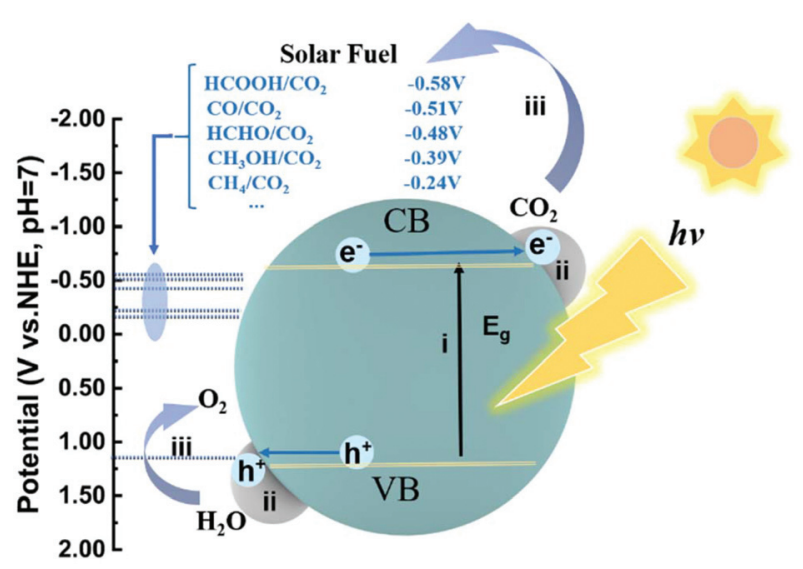

Fig. 1 Schematic illustration of the overall process for photocatalytic $\mathrm{CO}_{2}$ reduction with $\mathrm{H}_{2} \mathrm{O}$ over a semiconductor photocatalyst. The dotted lines indicate the thermodynamic potentials for water oxidation into $\mathrm{O}_{2}$ and $\mathrm{CO}_{2}$ reduction into $\mathrm{CH}_{4}, \mathrm{CH}_{3} \mathrm{OH}, \mathrm{HCHO}, \mathrm{CO}$ and $\mathrm{HCOOH}$, respectively. The numbers $\mathrm{i}$, ii and iii represent the three critical steps in photocatalytic $\mathrm{CO}_{2}$ reduction. 
solar light consists of about 95\% visible and infrared light. In the second step, a large fraction of electrons and holes may be consumed through recombination during migration. To facilitate charge separation and make full use of the photogenerated electrons, the rational design of active sites, such as defect creation, facet engineering and cocatalyst loading, is commonly applied. Otherwise, when photogenerated carriers are not consumed timely, taking an example of $\mathrm{Cu}_{2} \mathrm{O}$, accumulation of photogenerated holes on $\mathrm{Cu}_{2} \mathrm{O}$ would lead to its photocorrosion. ${ }^{24,25}$ In this regard, inorganic scavengers such as $\mathrm{Na}_{2} \mathrm{SO}_{3}$, and organic scavengers such as methanol and triethanolamine (TEOA) are commonly used as electron donors to consume the holes, which is obviously not economical. In the third step, $\mathrm{CO}_{2}$ molecule adsorption at the active sites is the prerequisite for subsequent reduction reactions.

When a $\mathrm{CO}_{2}$ molecule is adsorbed on a surface, the $\mathrm{CO}_{2}$ molecule can act as an electron donor and acceptor simultaneously. ${ }^{1}$ Each of the oxygen atoms with a lone pair of electrons can coordinate with surface Lewis acid sites, donating the electrons to these Lewis acid sites. Inversely, the carbon atom could gain electrons from Lewis base sites, forming a carbonate-like species. Thus, intentionally modifying the electronic properties of surface active sites can substantially tackle its dilemma of adsorption. To this end, surface acidity and alkalinity can significantly influence $\mathrm{CO}_{2}$ adsorption. Once the $\mathrm{CO}_{2}$ molecule interacts with the surface active site, the $\mathrm{CO}_{2}$ molecule can be polarized resulting in bent bonding for electron repulsion. The bent $\mathrm{CO}_{2}$ molecule can lower its LUMO (lowest unoccupied molecular orbital) level and thus make it easier for electron acceptance. ${ }^{26}$ Subsequently, multi-electron transfer together with the multi-step reduction of $\mathrm{CO}_{2}$, including cleavage of $\mathrm{C}=\mathrm{O}$ bonds and formation of $\mathrm{C}-\mathrm{H}$ bonds, leads to several different products (as summarized in the Table 1) depending on the specific active sites. Furthermore, since $\mathrm{CO}_{2}$ reduction is commonly performed in aqueous solution, water can be used as the electron donor. Thus the reduction of water into $\mathrm{H}_{2}$ often occurs as a competing reaction, resulting in electron consumption and decreased product selectivity. ${ }^{27}$ An anhydrous solvent (typically acetonitrile) may prevent $\mathrm{H}_{2}$ evolution; however, it is undoubtedly not an econ-

Table 1 The reduction potentials versus $\mathrm{NHE}$ at $\mathrm{pH} 7$ in aqueous solution, $25^{\circ} \mathrm{C}$ and $1 \mathrm{~atm}$ gas pressure

\begin{tabular}{lll}
\hline Product & Reaction & $\begin{array}{l}E^{\circ}(\mathrm{V} v s . \\
\text { NHE })\end{array}$ \\
\hline Hydrogen & $2 \mathrm{H}_{2} \mathrm{O}+2 \mathrm{e}^{-} \rightarrow 2 \mathrm{OH}^{-}+\mathrm{H}_{2}$ & -0.41 \\
Methane & $\mathrm{CO}_{2}+8 \mathrm{H}^{+}+8 \mathrm{e}^{-} \rightarrow \mathrm{CH}_{4}+2 \mathrm{H}_{2} \mathrm{O}$ & -0.24 \\
Methanol & $\mathrm{CO}_{2}+6 \mathrm{H}^{+}+6 \mathrm{e}^{-} \rightarrow \mathrm{CH}_{3} \mathrm{OH}+\mathrm{H}_{2} \mathrm{O}$ & -0.39 \\
Carbon monoxide & $\mathrm{CO}_{2}+2 \mathrm{H}^{+}+2 \mathrm{e}^{-} \rightarrow \mathrm{CO}+\mathrm{H}_{2} \mathrm{O}$ & -0.51 \\
Formic acid & $\mathrm{CO}_{2}+2 \mathrm{H}^{+}+2 \mathrm{e}^{-} \rightarrow \mathrm{HCOOH}+\mathrm{H}_{2} \mathrm{O}$ & -0.58 \\
Ethane & $2 \mathrm{CO}_{2}+14 \mathrm{H}^{+}+14 \mathrm{e}^{-} \rightarrow \mathrm{C}_{2} \mathrm{H}_{6}+4 \mathrm{H}_{2} \mathrm{O}$ & -0.27 \\
Ethanol & $2 \mathrm{CO}_{2}+6 \mathrm{H}^{+}+6 \mathrm{e}^{-} \rightarrow \mathrm{C}_{2} \mathrm{H}_{5} \mathrm{OH}+\mathrm{H}_{2} \mathrm{O}$ & -0.33 \\
Oxalate & $2 \mathrm{CO}_{2}+2 \mathrm{H}+2 \mathrm{e}^{-} \rightarrow \mathrm{H}_{2} \mathrm{C}_{2} \mathrm{O}_{4}$ & -0.87
\end{tabular}

omical strategy, and the lack of a hydrogen source also prohibits hydrocarbon products. As such, engineering active sites is the essential solution to obtain desired products with high activity and selectivity. Generally, the active sites are mainly closely related to the surface reactions, but also may influence charge transfer and light harvesting. In the following section, we will discuss in detail the developed strategies for engineering active sites and how they impact the key steps in improving the performance in photocatalytic $\mathrm{CO}_{2}$ reduction.

\section{Engineering active sites}

To achieve high activity and selectivity in photocatalytic $\mathrm{CO}_{2}$ reduction, the key point is to construct specific and effective active sites for facilitating the adsorption and activation of $\mathrm{CO}_{2}$ molecules. Generally, light absorbers lack efficient active sites. For this reason, various strategies have been developed for engineering active sites on the surface of diverse light absorbers, including creating surface vacancies, doping heteroatoms, modifying functional groups, loading metal nanoparticle cocatalysts, engineering crystal facets, dispersing heterogeneous single-site catalysts, anchoring homogeneous single-site catalysts, and modulating metal nodes/organic linkers in MOFs. Whatever the strategies are, the essence of engineering active sites is to adjust the localized electronic structure and environment to facilitate the adsorption and activation of $\mathrm{CO}_{2}$ molecules.

\subsection{Surface vacancies}

Perfect lattices or saturated coordination of intrinsic surfaces usually exhibit poor activity. Surface vacancies such as oxygen vacancy and metal vacancy have been proven to participate in many chemical reactions and also can serve as active sites playing an essential role in governing $\mathrm{CO}_{2}$ adsorption and activation. ${ }^{10,28-31}$ Enormous efforts have been dedicated to creating oxygen vacancies on the surface of light-harvesting semiconductors. ${ }^{32}$ Lee et al. have investigated $\mathrm{CO}_{2}$ adsorption at oxygen vacancies on the (110) facet of $\mathrm{TiO}_{2}$ by scanning tunneling microscopy (STM). ${ }^{33}$ After exposure to $\mathrm{CO}_{2}$ at $55 \mathrm{~K}$, as shown in Fig. 2a, the oxygen vacancy sites occupied by the $\mathrm{CO}_{2}$ features (marked with squares) are brighter than the bridging hydroxyl features $\left(\mathrm{OH}_{\mathrm{b}}\right)$ (marked with circles), suggesting the interaction between the $\mathrm{CO}_{2}$ molecule and vacancy sites. The corresponding schematic of a $\mathrm{CO}_{2}$ molecule adsorbed at an oxygen vacancy $\left(\mathrm{V}_{\mathrm{O}}\right)$ site is shown in Fig. $2 \mathrm{~b}$. The adsorption and activation of $\mathrm{CO}_{2}$ on the surface oxygen vacancy sites also can be revealed by the calculated adsorption energy $\left(E_{\text {ads }}\right) .^{32}$ The existence of oxygen vacancies greatly promoted $\mathrm{CO}_{2}$ adsorption with $-0.377 \mathrm{eV}$ for $\mathrm{Sr}_{2} \mathrm{Bi}_{2} \mathrm{Nb}_{2} \mathrm{TiO}_{12}$ with abundant oxygen vacancies in contrast to $-0.125 \mathrm{eV}$ for the sample without oxygen vacancies. Such a strong covalent interaction between an oxygen vacancy and $\mathrm{CO}_{2}$ molecule is confirmed by the charge difference distribution and electronic location function (Fig. 2c-f). Moreover, the oxygen vacancies not only can serve as active sites to enhance $\mathrm{CO}_{2}$ adsorption but also 

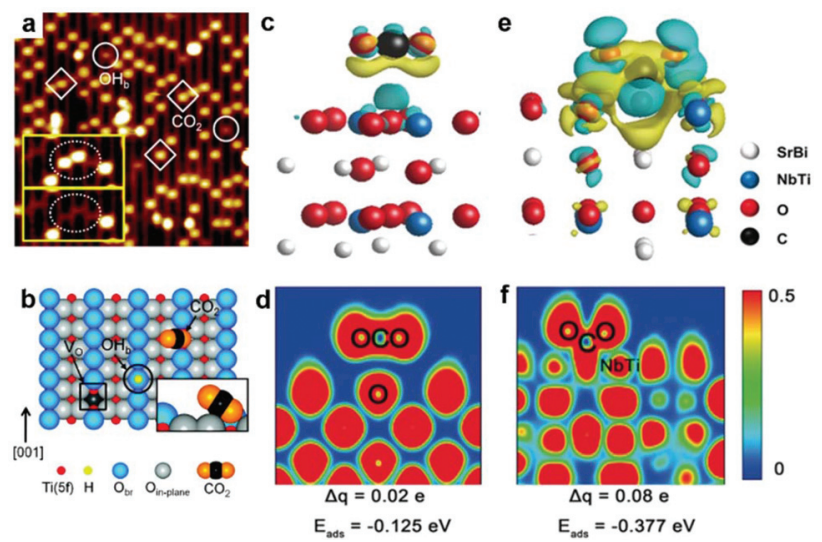

Fig. 2 (a) STM image $\left(1.5 \mathrm{~V}, 5 \mathrm{pA}, 15 \mathrm{~nm} \times 15 \mathrm{~nm}\right.$ ) of the $\mathrm{TiO}_{2}(110)$ surface after adsorption of $\mathrm{CO}_{2}$ at $55 \mathrm{~K}$. The $\mathrm{CO}_{2}$ and $\mathrm{OH}_{\mathrm{b}}$ features are marked with squares and circles, respectively. (b) Schematic illustration of a bridging hydroxyl $\left(\mathrm{OH}_{\mathrm{b}}\right)$ (black circle), an oxygen vacancy defect $\left(\mathrm{V}_{\mathrm{O}}\right)$ (black square), and a $\mathrm{CO}_{2}$ molecule adsorbed at a $\mathrm{V}_{\mathrm{O}}$ site on the reduced $\mathrm{TiO}_{2}$ (110) surface. Reproduced with permission from ref. 33, copyright 2011 American Chemical Society. (c) Differential charge distribution and (d) electronic location function for the oxygen-free sample. (e) Differential charge distribution and ( $f$ ) electronic location function for the oxygen-abundant sample. Reproduced with permission from ref. 32, copyright 2019 John Wiley and Sons.

broaden light absorption. For example, the presence of oxygen vacancies in the $\mathrm{Bi}_{2} \mathrm{WO}_{6}$ photocatalyst can extend the light-harvesting from ultraviolet to the near-infrared region for photocatalytic $\mathrm{CO}_{2}$ reduction, which is attributed to the newly generated in-gap defect band. ${ }^{34}$

Although the oxygen vacancies have shown good performance in photocatalytic $\mathrm{CO}_{2}$ reduction, the regeneration of the oxygen vacancies is still a tough problem since pristine oxygen vacancies are easily filled up by the $\mathrm{O}$ atom from $\mathrm{CO}_{2}$ during the reaction process and thus are gradually inactivated with poor stability. To address this issue, Zhang et al. reported a highly efficient $\mathrm{BiOCl}$ nanoplate with reproducible oxygen vacancies for the photocatalytic reduction of $\mathrm{CO}_{2}$ to $\mathrm{CO}$ and $\mathrm{CH}_{4} \cdot{ }^{31}$ The photoreduction-induced oxygen vacancy can be easily regenerated by light irradiation due to the high density of the oxygen atom and the low energy of the $\mathrm{Bi}-\mathrm{O}$ bond. As schematically illustrated in Fig. 3a, oxygen regeneration is induced by the process that outer Bi can easily escape from the lattice after illumination and then the high density surface $\mathrm{O}$ atoms with a low formation energy are readily released to balance the charge, rendering the formation of oxygen vacancies. The oxygen vacancies recovered in light-treated BiOCl (denoted as BiOCl-LT) can be further confirmed by XPS (Fig. 3b and c), in which the valence change from $\mathrm{Bi}^{3+}$ (partially converted) to $\mathrm{Bi}^{0}$ and $\mathrm{Bi}^{3+x}$ after light irradiation promotes the high binding energy component in the O 1s XPS spectra.

In addition to oxygen vacancy, metal vacancies also can serve as excellent active sites for photocatalytic $\mathrm{CO}_{2}$ reduction. Xie's group have built an ideal model of two-dimensional $\mathrm{ZnInS}_{2}$ atomic layers with a tunable concentration of $\mathrm{Zn}$
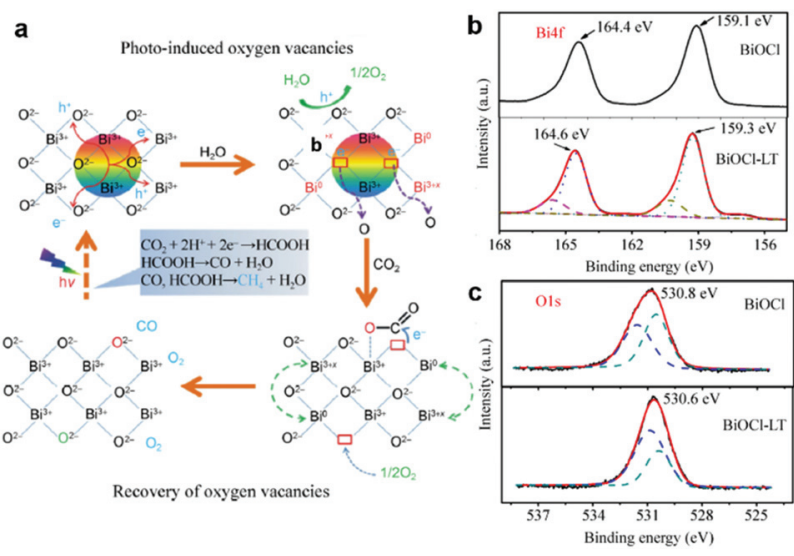

Fig. 3 (a) Possible reaction pathways for $\mathrm{CO}_{2}$ photoreduction with $\mathrm{H}_{2} \mathrm{O}$ on $\mathrm{BiOCl}$ nanoplates. (b) XPS spectra of the $\mathrm{Bi}_{4 \mathrm{f}}$ region and (c) the $\mathrm{O}_{1 \mathrm{~s}}$ region for $\mathrm{BiOCl}$ and $\mathrm{BiOCl}-\mathrm{LT}$ nanoplates. Reproduced with permission from ref. 31, copyright 2015 Springer.

vacancies to elucidate the relationship between defect sites and photocatalytic $\mathrm{CO}_{2}$ reduction. ${ }^{35}$ Aberration-corrected scanning transmission electron microscopy (Fig. 4a-e) directly manifests the distinct zinc vacancy concentrations at the atomic level, which is also confirmed by electron spin resonance (ESR) analysis (Fig. 4f). The abundant $\mathrm{Zn}$ vacancies not only act as active sites for higher $\mathrm{CO}_{2}$ adsorption capacity, but also provide increased photo-absorption, stronger surface hydrophilicity and higher efficiency of electron-hole separ-


Fig. 4 Characterization of $\mathrm{V}_{\mathrm{Zn}}$-rich one-unit-cell $\mathrm{ZnIn}_{2} \mathrm{~S}_{4}$ (ZIS) layers obtained at $200^{\circ} \mathrm{C}$. HAADF-STEM images (a, b) and intensity profile (c) corresponding to the dark cyan arrow in panel $b$. The corresponding crystal structures (d) and SAED patterns (e). (f) EPR spectra of $\mathrm{V}_{Z n}$-rich and $V_{Z n}$-poor one-unit-cell ZIS layers. Reproduced with permission from ref. 35. copyright 2017 American Chemical Society. 
ation. As a result, ultrathin $\operatorname{ZnIn}_{2} \mathrm{~S}_{4}$ nanosheets with rich zinc vacancies exhibit a CO yield rate of $33.2 \mu \mathrm{mol} \mathrm{g}{ }^{-1} \mathrm{~h}^{-1}$, around 3.6 times higher than that of the ultrathin $\mathrm{ZnIn}_{2} \mathrm{~S}_{4}$ nanosheets with limited zinc vacancies.

Overall, engineering surface vacancies is an important strategy for tuning photocatalytic $\mathrm{CO}_{2}$ reduction. This strategy provides abundant adsorption sites, promotes electron-hole pair separation efficiency and fulfils broad-spectrum light harvesting, thus leading to excellent activity for photocatalytic $\mathrm{CO}_{2}$ reduction. However, the density and stability of the vacancies still need to be optimized for more active and durable photocatalytic $\mathrm{CO}_{2}$ reduction given that oxygen vacancy can be filled up leading to downward activity during the $\mathrm{CO}_{2}$ dissociation process. $^{31}$

\subsection{Heteroatom doping}

The local electronic structure of the active sites is a critical factor determining their activity and selectivity in photocatalytic $\mathrm{CO}_{2}$ reduction. Introducing heteroatoms into semiconductors or quantum dots as active sites or nearby the active sites is an alternative approach to modify their local electronic structure for governing activity and selectivity in photocatalytic $\mathrm{CO}_{2}$ reduction. To date, various metal cations (i.e., $\mathrm{Fe},{ }^{36} \mathrm{Co},{ }^{37}$ $\mathrm{Ni},{ }^{38,39} \mathrm{Cu},{ }^{40} \mathrm{In},{ }^{41} \mathrm{Zr}^{42}$ ) and nonmetal atoms (i.e., $\mathrm{S},{ }^{43} \mathrm{P},{ }^{44} \mathrm{~B},{ }^{45}$ $\mathrm{N}^{46} \mathrm{~F}^{47} \mathrm{I}^{48}$ ) have been investigated as dopants in semiconductor lattices to modulate electronic structures or serve as active sites for photocatalytic $\mathrm{CO}_{2}$ reduction. Wang et al. have doped Co into $\mathrm{BiVO}_{4}$ to increase the electron density around $\mathrm{O}$ anions, serving as a Lewis base active site to facilitate $\mathrm{CO}_{2}$ activation and electron transfer to $\mathrm{CO}_{2}$ molecules. ${ }^{37}$ In addition to activity, the correlation between elemental doping and selectivity regulation for photocatalytic $\mathrm{CO}_{2}$ reduction has also been established. Xie's group have reported that Ni-doped $\mathrm{ZnCo}_{2} \mathrm{O}_{4}$ atomic layers exhibit a 3.5-time higher $\mathrm{CO}$ selectivity than undoped $\mathrm{ZnCo}_{2} \mathrm{O}_{4}$ atomic layers for photocatalytic $\mathrm{CO}_{2}$ reduction to $\mathrm{CO}$ and $\mathrm{CH}_{4} \cdot{ }^{38}$ Moreover, the competing $\mathrm{H}_{2}$ evolution can be significantly suppressed by heteroatom doping. Our research group has developed Ni-doped CdS quantum dots for $\mathrm{CO}_{2}$ reduction into $\mathrm{CO}$ and $\mathrm{CH}_{4} \cdot{ }^{39}$ The $\mathrm{Ni}^{2+}$ dopants serving as active sites can substantially suppress $\mathrm{H}_{2}$ evolution as compared with pristine CdS (Fig. 5a). In addition, the photoexcited electrons can be effectively trapped at the doped $\mathrm{Ni}$ atoms in sulfur vacancies and relax to the shallow charge trap state, thus substantially promoting charge separation, as confirmed by the reduced intensity of the signal for $\mathrm{Ni}^{2+}$ upon light irradiation in ESR (Fig. 5b). This argument was further confirmed by the enhanced photoluminescence (PL) around $600 \mathrm{~nm}$ (Fig. 5c), and supported by the reduced PL at 500-550 $\mathrm{nm}$ for radiative recombination in the presence of methyl viologen $\left(\mathrm{MV}^{2+}\right)$ (Fig. 5d), an agent to sacrifice surface electrons of QDs. In situ diffuse reflectance infrared Fourier transform spectroscopy (DRIFTS) suggests that the $\mathrm{Ni}^{2+}$ active sites capture photo-generated electrons and adsorb $\mathrm{CO}_{2}$ molecules to form the Ni-COOH complex (Fig. 5e and $\mathrm{f}$ ), as indicated by the peaks located at $1305 \mathrm{~cm}^{-1}, 1412 \mathrm{~cm}^{-1}$, and $1640 \mathrm{~cm}^{-1}$ corresponding to $\mathrm{C}-\mathrm{OH}, \mathrm{C}-\mathrm{O}$, and $\mathrm{C}=\mathrm{O}$ stretching,
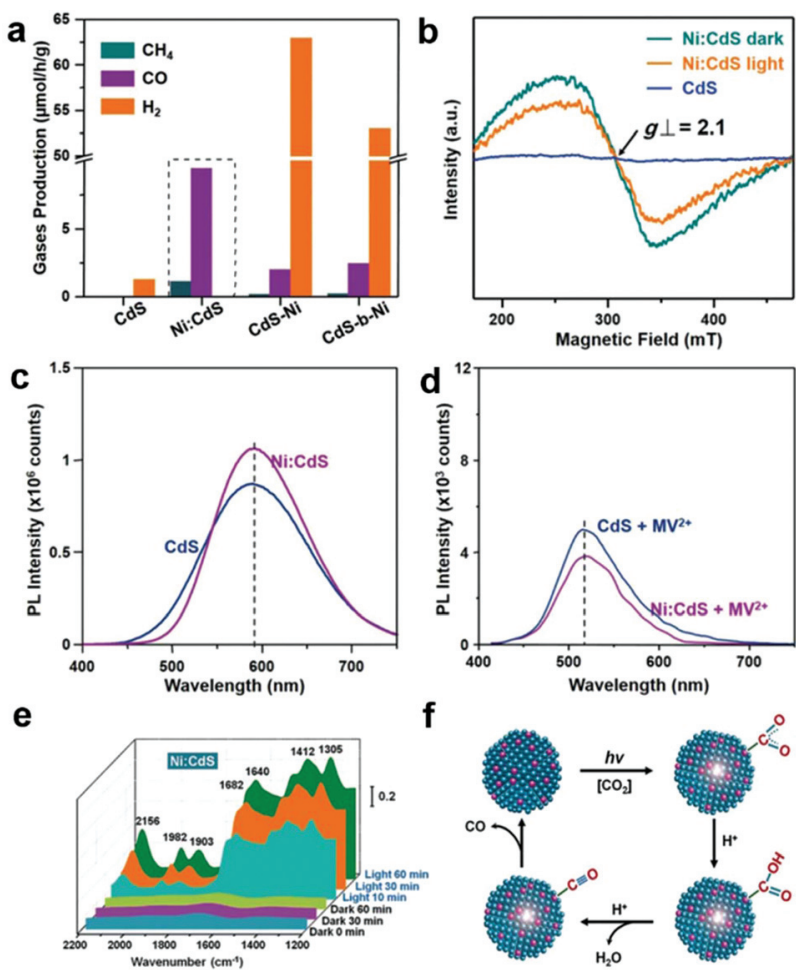

Fig. 5 Gaseous products by Ni-CdS (0.26\%) QDs in photocatalytic $\mathrm{CO}_{2}$ reduction. (b) EPR spectra of CdS QDs and Ni-CdS (0.26\%) QDs before and after illumination. (c) $\mathrm{PL}$ emission spectra of bare $\mathrm{CdS}$ and $\mathrm{Ni}$ (0.26\%):CdS QDs. (d) PL emission spectra of bare CdS and $\mathrm{Ni}(0.26 \%$ : CdS QDs in the presence of $\mathrm{MV}^{2+}$. (e) In situ FTIR spectra. (f) Proposed mechanism for photocatalytic $\mathrm{CO}_{2}$ reduction using $\mathrm{Ni}$ :CdS QDs. Reproduced with permission from ref. 39, copyright 2018 John Wiley and Sons.

respectively. Subsequently, the $\mathrm{Ni}-\mathrm{COOH}$ complex dehydrates to the Ni-CO complex as indicated by two stretching bands at 1903 and $1982 \mathrm{~cm}^{-1}$, which accounts for the different selectivity.

Apart from metal dopants, non-metals also can be introduced into light-absorption substrates. Non-metal doping into graphitic carbon nitride $\left(\mathrm{g}-\mathrm{C}_{3} \mathrm{~N}_{4}\right)$ to modulate coordination moieties and local electronic structures is widely investigated. ${ }^{49} \mathrm{Fu}$ et al. have doped $\mathrm{B}$ into the $\mathrm{g}-\mathrm{C}_{3} \mathrm{~N}_{4}$ scaffold between adjacent tri-s-triazine units by coordination with twocoordinated $\mathrm{N}$ atoms. ${ }^{45}$ The $\mathrm{B}$ dopants serving as active sites can change the adsorption of the $\mathrm{CO}$ intermediate to promote $\mathrm{CH}_{4}$ production. Furthermore, theoretical calculations reveal that $\mathrm{B}$ atom doping can make the electron excitation much easier and improve the charge transfer and localization as well as reaction dynamics, thus significantly enhancing the catalytic performance. Shown et al. have fabricated a carbon-doped $\mathrm{SnS}_{2}$ nanostructure for photocatalytic $\mathrm{CO}_{2}$ reduction, in which the carbon dopants are incorporated as excellent electron acceptor centers to suppress the charge recombination during the electron transfer process. ${ }^{50}$ Furthermore, carbon doping shrank the band gap from $2.54 \mathrm{eV}$ to $2.43 \mathrm{eV}$, and significantly enlarged the light absorption range from a visible-light wave- 
length of $530 \mathrm{~nm}$ toward a longer wavelength, which is the most intense region in the solar spectrum. Thus the synthesized $\mathrm{SnS}_{2}-\mathrm{C}$ photocatalyst significantly enhanced the activity in selective photocatalytic $\mathrm{CO}_{2}$ reduction to acetaldehyde under visible light with a photochemical quantum efficiency of above $0.7 \%$.

Overall, doping metal and nonmetal atoms into light-harvesting quantum dots and semiconductors can significantly impact the $\mathrm{CO}_{2}$ adsorption state as the addition of the heteroatoms can induce increased localized electron density, in favor of transferring electrons to $\mathrm{CO}_{2}$ molecules. Meanwhile, dopants in a pristine lattice can generate a new impurity level below the maximum conduction band where photo-generated electrons relax to, which is beneficial for photo-generated electron-hole separation and broad-spectrum light absorption. ${ }^{28,51}$ Therefore, heteroatom doping is an alternative strategy for integrating active sites to bind $\mathrm{CO}_{2}$ molecules, modulating the local electronic structure nearby adsorbed $\mathrm{CO}_{2}$ molecules to regulate selectivity, and generating defect states or impurity energy levels so as to improve the light utilization efficiency and electron-hole separation efficiency.

\subsection{Surface acidity and alkalinity}

Lewis alkalinity refers to the ability of giving an electron pair to a Lewis acid molecule. ${ }^{52}$ Since $\mathrm{CO}_{2}$ is a weak acidic molecule, Lewis basic sites possess the capacity of capturing and adsorbing $\mathrm{CO}_{2}$ molecules. As such, constructing Lewis basic sites is an alternative method of generating $\mathrm{CO}_{2}$ binding sites. As discussed above, it is a versatile method to engineer oxygen vacancies on the surface of metal oxide semiconductors serving as active sites. The hydroxyl groups tend to produce on oxygen vacancies in the presence of water forming Lewis basic sites, which are beneficial for the adsorption of weak acidic $\mathrm{CO}_{2}$ molecules. ${ }^{53}$ Some solid basic hydroxides or metal oxides such as $\mathrm{NaOH}$ and $\mathrm{MgO}$ can interact with the carbon atom in $\mathrm{CO}_{2}$ because of their basic nature. ${ }^{52,54,55}$ Damien et al. have investigated the actual structure of the $\mathrm{CO}_{2}$ species adsorbed on the magnesium oxide surface by combining experimental infrared spectroscopy and density functional theory (DFT) study. ${ }^{52}$ In addition, modifying a surface with hydroxyl groups can be realized by alkali treatment such as $\mathrm{NaOH} .{ }^{13}$ Meng et al. have modified $\mathrm{TiO}_{2}$ with $\mathrm{NaOH}$ to promote $\mathrm{CO}_{2}$ chemisorption. ${ }^{55}$ Increasing the loading amount of $\mathrm{NaOH}$ can facilitate the adsorption of $\mathrm{CO}_{2}$ on a surface with enhanced $\mathrm{CH}_{4}$ production (Fig. 6a and b). However, excessive $\mathrm{NaOH}$ loading leads to surface encapsulation and induces the aggregation of $\mathrm{TiO}_{2}$ nanoparticles, which hinders the $\mathrm{CH}_{4}$ production. Apart from basic hydroxides and metal oxides as common Lewis bases, surface functionalization with a basic group such as an amino group has also been widely employed for $\mathrm{CO}_{2}$ capture. ${ }^{56}$ Liu et al. have reported a one-step preparation of P-doped $\mathrm{C}_{3} \mathrm{~N}_{4}$ nanocrystals by the thermal annealing method. ${ }^{44}$ The interstitial doping of phosphorus creates an amino-rich surface confirmed by the Fourier transform infrared spectrum (Fig. 6c), which is conducive to the adsorption of $\mathrm{CO}_{2}$ and conversion into $\mathrm{CO}$ and $\mathrm{CH}_{4}$ (Fig. 6d).
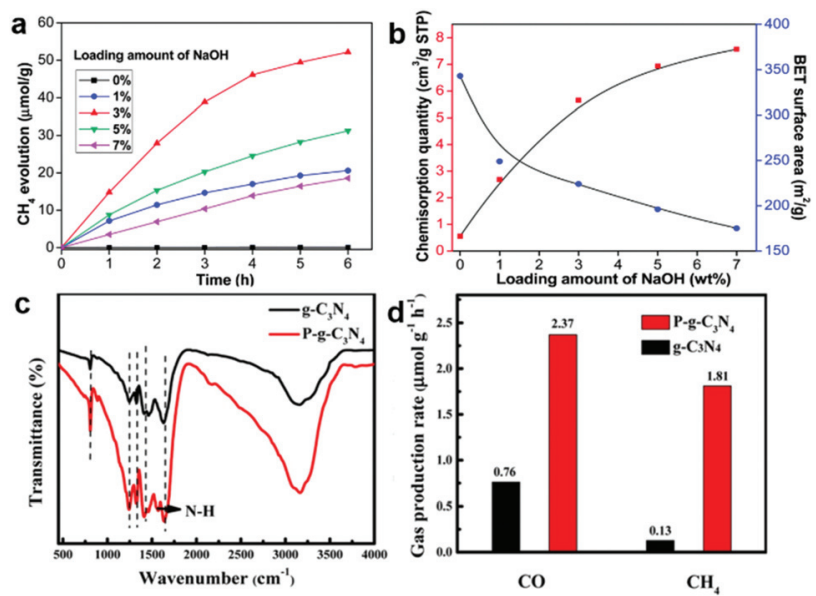

Fig. 6 (a) Time dependence of $\mathrm{CH}_{4}$ evolution. (b) Cumulative $\mathrm{CO}_{2}$ pulse chemisorption quantity and BET surface area of $\mathrm{NaOH}-\mathrm{TiO}_{2} \mathrm{com}-$ posites. Reproduced with permission from ref. 55, copyright 2014 Royal Society of Chemistry. (c) FT-IR spectra and (d) $\mathrm{CO}$ and $\mathrm{CH}_{4}$ yield. Reproduced with permission from ref. 44, copyright 2018 American Chemical Society.

Furthermore, frustrated Lewis pairs (FLPs) consist of sterically hindered Lewis base-acid pair, which can serve as active sites for both binding $\mathrm{CO}_{2}$ and heterolytically dissociating $\mathrm{H}_{2}$. In view of this, FLPs provide a promising approach for $\mathrm{CO}_{2}$ activation and subsequent stepwise hydrogenation to produce hydrocarbon fuels. Surface modification of hydroxyl groups on metal oxides to form surface FLPs, a Lewis basic surface hydroxide site and a Lewis acidic coordinatively unsaturated surface metal site nearby an oxygen vacancy, have been reported as active sites to effectively improve $\mathrm{CO}_{2}$ adsorption and activation. ${ }^{57,58}$ However, FLPs require significant steric hindrance to prevent the formation of inactive Lewis baseLewis acid adducts in solution. ${ }^{59}$ The bulky substituents in FLPs may increase the energy required to activate the $\mathrm{CO}_{2}$. Thus it is important to explore other possibilities to stabilize Lewis pairs (LPs) that do not involve steric hindrance. To address this issue, Johnson's group has proposed a strategy for incorporating LPs into porous MOFs for the catalytic reduction of $\mathrm{CO}_{2}$ with $\mathrm{H}_{2} \cdot{ }^{59}$ As shown in Fig. 7a-c, Lewis pairs (LPs) possessing both Lewis acid (B) and base $\left(\mathrm{N}_{\mathrm{b}}\right)$ sites within a single molecule have been successfully incorporated into UiO-66 MOFs as excellent candidates for both $\mathrm{CO}_{2}$ adsorption and subsequent stepwise hydrogenation to produce formic acid. The LPs retain their chemical activity being able to facilely bind $\mathrm{CO}_{2}$. According to the calculation, $\mathrm{CO}_{2}$ can be reduced to $\mathrm{HCOOH}$ via a lower energy barrier pathway in contrast to the sample without LP functionalization (Fig. 7d).

In brief, surface acidity and alkalinity significantly impact the adsorption and activation of $\mathrm{CO}_{2}$ molecules. Building Lewis basic sites as well as constructing FLPs or LPs on surfaces via modifying the basic group/amphiphilic molecule is a promising approach to engineer active sites for favourable $\mathrm{CO}_{2}$ adsorption and lower energy barriers in subsequent steps. However, characterization of the Lewis basic sites is vital for 
a

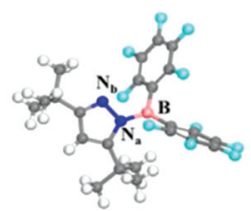

b

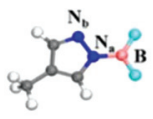

๑:B e:N ๑:F

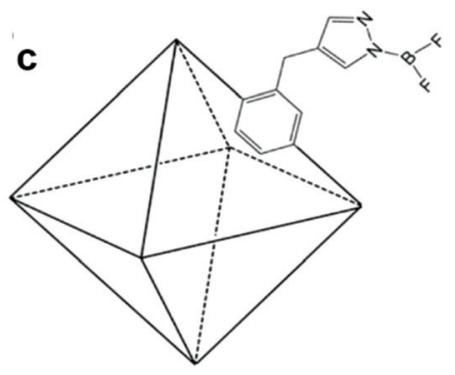

d

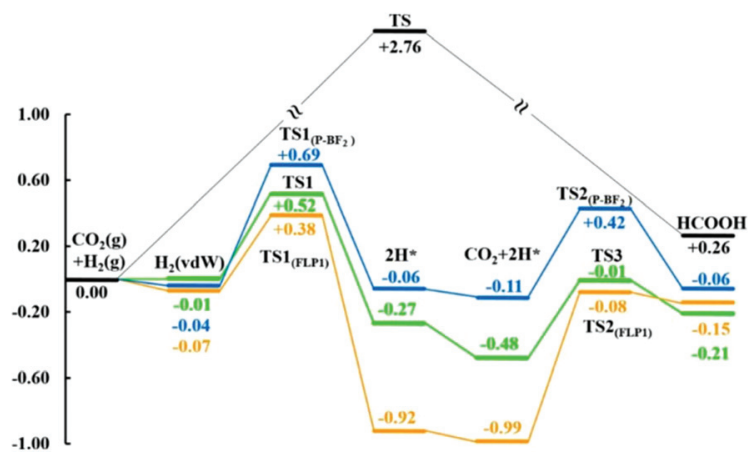

Fig. 7 Structure of frustrated Lewis pairs $\left(F L P_{1}\right)$ (a) and $P-B F_{2}$ (b). (c) Schematic of a UiO-66 primitive cell functionalized with $\mathrm{P}_{-}-\mathrm{BF}_{2}$. (d) Relative potential energy surfaces for gas phase $\mathrm{CO}_{2}$ hydrogenation without a catalyst (black), catalyzed by $\mathrm{FLP}_{1}$ (orange), catalyzed by $\mathrm{P}-\mathrm{BF}_{2}$ (blue), and catalyzed by UiO-66-P-BF 2 (green). Reproduced with permission from ref. 59, copyright 2015 American Chemical Society.

the deeper understanding between catalytic activity and surface state, to which more attention should be paid.

\subsection{Metal nanoparticle cocatalysts}

Incorporation of metal nanoparticle cocatalysts providing active sites can make great contribution in enhancing the surface reaction kinetics through lowering the activation energy, which greatly improves the activity and selectivity of photocatalysts for $\mathrm{CO}_{2}$ reduction. Beyond that, metal nanoparticle cocatalysts can significantly improve the charge separation efficiency by the formation of a Schottky junction especially for noble metals. ${ }^{6,60}$ Engineering mono-component metal nanoparticles, such as $\mathrm{Pt}, \mathrm{Pd}, \mathrm{Au}, \mathrm{Ag}, \mathrm{Rh}, \mathrm{Cu}, \mathrm{Ni}$, and Co, as cocatalysts supported on semiconductors is a simple and effective way to construct active sites. ${ }^{61-64}$ Constructing metal nanoparticle cocatalysts could induce charge redistribution on the surface after photoexcitation, resulting in discrepant electronic acceptance ability for adsorbed intermediates. As a result, we can integrate metal nanoparticle cocatalysts to regulate product selectivity.

Among all the noble metals, Pt possesses the highest work function (5.6 eV), implying strong electron-extracting ability. ${ }^{65}$ Therefore, $\mathrm{Pt}$ as a cocatalyst has been extensively investigated for loading onto various semiconductors. ${ }^{54,64,66}$ Xie et al. have examined a series of noble metal nanoparticle cocatalysts loaded on $\mathrm{TiO}_{2}$ for photocatalytic $\mathrm{CO}_{2}$ reduction. ${ }^{54}$ Interestingly, the yield of $\mathrm{CH}_{4}$ formation increases in the sequence of $\mathrm{Ag}<\mathrm{Rh}<\mathrm{Au}<\mathrm{Pd}<\mathrm{Pt}$, in good accordance with the increase in work function $\mathrm{Ag}(4.26 \mathrm{eV})<\mathrm{Rh}(4.98 \mathrm{eV})<\mathrm{Au}$ $(5.10 \mathrm{eV})<\mathrm{Pd}(5.12 \mathrm{eV})<\mathrm{Pt}(5.65 \mathrm{eV})$, as well as the efficiency of carrier separation. This result indicates that the strongest capacity of Pt for extracting photogenerated electrons gives the enhanced selectivity of $\mathrm{CH}_{4}$ in $\mathrm{CO}_{2}$ reduction. However, the severe competition of $\mathrm{H}_{2}$ evolution occurring likewise to $\mathrm{Pt}$ and Pd would consume a large quantity of the photoexcited electrons and newly released $\mathrm{H}$ atoms, both of which are necessary for the follow-up reduction of the $\mathrm{CO}$ intermediate into target $\mathrm{CH}_{4}$. Thus, the target $\mathrm{CH}_{4}$ product will be sacrificed with low selectivity inevitably. In this regard, our research group has proposed a hydridation strategy to incorporate $\mathrm{H}$ atoms into the lattice of metal cocatalysts prior to the photocatalytic $\mathrm{CO}_{2}$ reduction reaction. ${ }^{27}$ The hydride $\mathrm{PdH}_{0.43}$ obtained through hydriding Pd cocatalysts significantly suppressed competing $\mathrm{H}_{2}$ revolution and facilitated the conversion of the $\mathrm{CO}$ intermediate into the final $\mathrm{CH}_{4}$ product. As a result, the selectivity for $\mathrm{CH}_{4}$ production is increased from $3.2 \%$ to $63.6 \%$ on $\operatorname{Pd}\{100\}$ and from $15.6 \%$ to $73.4 \%$ on $\mathrm{Pd}$ $\{111\}$, with excellent photocatalytic durability being maintained in successive cycles (Fig. 8a-d). The enhanced performance is attributed to the fact that hydriding promotes the electron trapping on $\mathrm{PdH}_{0.43}$ sites and improves the charge separation, which ensures adequate electrons and $\mathrm{H}$ atoms for the reduction of $\mathrm{CO}_{2}$ into $\mathrm{CH}_{4}$ (Fig. 8e).

The composition of the cocatalyst could play an essential role in regulating selectivity. Alloying is a promising approach
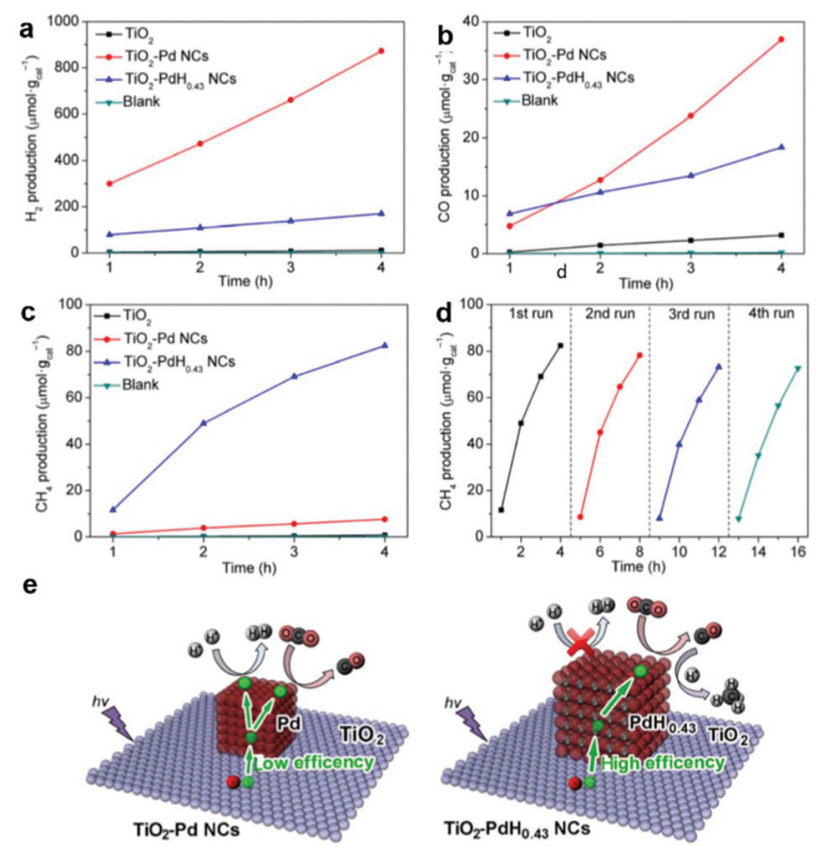

Fig. 8 Time-dependent production of (a) $\mathrm{H}_{2}$, (b) $\mathrm{CO}$, and (c) $\mathrm{CH}_{4}$ in photocatalytic $\mathrm{CO}_{2}$ reduction with bare $\mathrm{TiO}_{2}, \mathrm{TiO}_{2}-\mathrm{Pd} \mathrm{NCs}$, and $\mathrm{TiO}_{2}-$ $\mathrm{PdH}_{0.43} \mathrm{NCs}$ under UV $\left(\lambda<400 \mathrm{~nm}\right.$ ) irradiation. (d) Cycling $\mathrm{CH}_{4}$ evolution with $\mathrm{TiO}_{2}-\mathrm{PdH}_{0.43} \mathrm{NCs}$ in photocatalytic $\mathrm{CO}_{2}$ reduction. (e) Schematics illustrating the photocatalytic reactions between $\mathrm{CO}_{2}$ and $\mathrm{H}_{2} \mathrm{O}$ for the $\mathrm{TiO}_{2}-\mathrm{Pd} \mathrm{NCs}$ and $\mathrm{TiO}_{2}-\mathrm{PdH}_{0.43} \mathrm{NCs}$. Reproduced with permission from ref. 27, copyright 2017 Springer. 
to adjust the surface composition of mono-component metal cocatalysts. Binary alloy cocatalysts (i.e., $\mathrm{Au} / \mathrm{Cu},{ }^{67} \mathrm{Au} / \mathrm{Ag}^{68}$ ) have been reported to exhibit a synergistic effect on promoting the photocatalytic $\mathrm{CO}_{2}$ reduction. Ye's group revealed that the $\mathrm{Au}-$ $\mathrm{Cu}$ bimetallic alloy nanoparticles as a cocatalyst in photocatalytic $\mathrm{CO}_{2}$ reduction exhibited significantly improved selectivity for hydrocarbon species production instead of $\mathrm{CO}$ evolution owing to the synergetic effect, in which $\mathrm{Au}$ atoms favour $\mathrm{CO}$ desorption and $\mathrm{Cu}$ atoms boost the formation of hydrogenation species. ${ }^{67}$ Given the abovementioned facts, the composition of the cocatalyst can be regulated to affect the local charge density at the adsorption site, which would influence the adsorption of $\mathrm{CO}_{2}$ molecules as well as intermediates. Based on their intrinsic nature, various metals could display different abilities for the absorption of intermediates. For instance, there is strong interaction between $\mathrm{Pt}$ and $\mathrm{CO}$ whereas only weak interaction takes places between $\mathrm{Ag}$ and CO. ${ }^{65}$ Thus understanding the inherent electronic properties of different metals is instructional to construct suitable metal nanoparticle cocatalysts in terms of regulating activity and selectivity in photocatalytic $\mathrm{CO}_{2}$ reduction.

In general, a semiconductor serving as a light absorber requires a suitable band structure, in which both the conduction band and valence band can have sufficient redox potentials to drive the corresponding reduction/oxidation reactions. ${ }^{69}$ In photocatalytic reactions, tuning reduction activity based on the band bending near the semiconductor surface can be achieved by loading metal nanoparticle cocatalysts. ${ }^{70}$ When the semiconductor contacts with metal nanoparticles forming an interface, their different Fermi level $\left(E_{\mathrm{f}}\right)$ and work function will result in the formation of an internal field that drives electrons to flow toward the more positive $E_{\mathrm{f}}$ side until achieving an equilibrium state, leading to an upward bending of the band edge for the n-type semiconductor, but a downward band bending for the p-type semiconductor. ${ }^{3,71}$ The surface with upward band bending exhibits higher oxidation but lower reduction activities, while the surface with downward band bending results in the reverse outcome.

\subsection{Facet engineering}

Diverse morphologies of metallic cocatalysts and semiconductors have been fabricated for photocatalytic $\mathrm{CO}_{2}$ reduction and exhibited different performance. Substantially, the morphology is determined by the proportion of miscellaneous exposed facets. A chosen facet can exhibit a unique electronic structure owing to its specific atomic arrangement and coordination, which is crucial to the adsorption of reactant molecules and desorption of intermediates. ${ }^{8,72}$ In this regard, facet engineering by altering the proportion of specific exposed facets can substantially tune the ratio of different coordination atoms on the surface and regulate surface charge density. As such, selectively exposing specific active facets would make a great contribution to the enhancement of activity. ${ }^{23,73,74}$ In contrast to low index facets, high index facets generally possess a higher density of low-coordinated atoms (e.g., steps, terraces and kinks) serving as more efficient active sites for surface catalytic reactions. ${ }^{75}$ Bai's research group has compared the performance of high-index (730) facet-covered $\mathrm{PtCu}$ concave nanocubes and (100) facet-enclosed $\mathrm{PtCu}$ nanocubes as cocatalysts loading on light-harvesting $\mathrm{C}_{3} \mathrm{~N}_{4}$ for the photocatalytic reduction of $\mathrm{CO}_{2}$ to $\mathrm{CH}_{4}{ }^{75}$ In comparison with low-index (110) facets, high-index (730) facets showed a higher yield of $\mathrm{CO}$ and $\mathrm{CH}_{4}$ on account of their higher density of lowcoordinated Pt atoms as catalytically active sites and higher $\mathrm{CO}_{2}$ adsorption energy. In parallel, Yu's group has demonstrated that tetrahedral Pd nanoparticles with exposed $\{111\}$ facets functioned as a more efficient cocatalyst loading on $\mathrm{g}-\mathrm{C}_{3} \mathrm{~N}_{4}$ for photocatalytic $\mathrm{CO}_{2}$ reduction, as compared to cubic Pd nanoparticles with exposed $\{100\}$ facets. ${ }^{76}$ DFT calculations confirmed that the $\operatorname{Pd}\{111\}$ surface showed more preferable $\mathrm{CO}_{2}$ adsorption capability and $\mathrm{CH}_{3} \mathrm{OH}$ desorption capability as compared to the $\operatorname{Pd}\{100\}$ surface.

In addition to metallic cocatalysts, facet engineering also works for metal oxide semiconductors. Gao et al. have reported that hexagonal platelet $\mathrm{Co}_{3} \mathrm{O}_{4}$ exposing $\{112\}$ facets enable superior activity to $\{110\}$ facets for the photocatalytic reduction of $\mathrm{CO}_{2}$ to $\mathrm{CO}$ along with a visible-light photo-sensitizer. ${ }^{77} \mathrm{DFT}$ calculations (Fig. 9a) further confirmed that the exposed $\{112\}$ facets favour the adsorption of $\mathrm{CO}_{2}$ and the subsequent reduction to $\mathrm{CO}$ via $\mathrm{COOH}$, which accounts for the facet effect on photocatalytic $\mathrm{CO}_{2}$ reduction. Constructing co-exposed crystal facets within a single crystal is regarded as an attractive strategy for realizing efficient surface charge separation, in which the photo-generated electrons and holes would transfer to anisotropic facets for spatial separation. Toward this strategy, Yu's group has fabricated and optimized the ratio of coex-

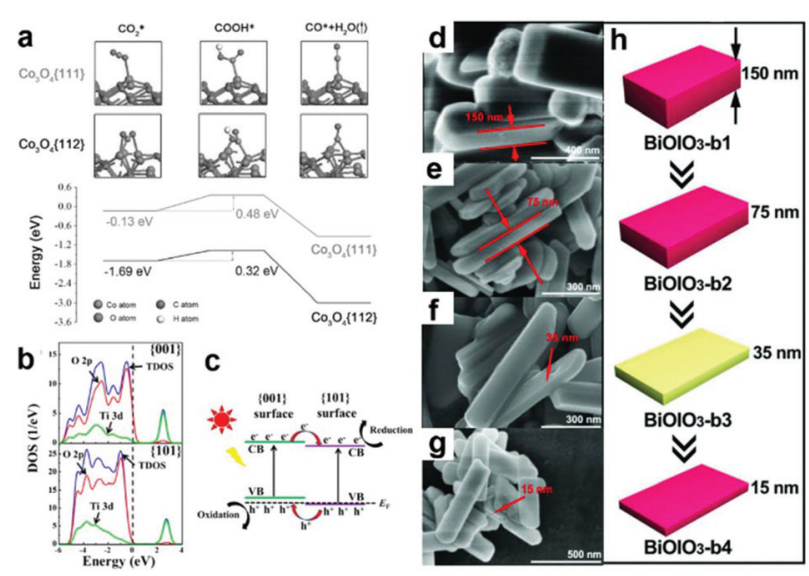

Fig. 9 (a) DFT calculation of adsorption and reduction of $\mathrm{CO}$ on $\mathrm{Co}_{3} \mathrm{O}_{4}$ surfaces. Free energy diagram describes the $\mathrm{COOH}^{*}$ intermediate from $\mathrm{CO}_{2}$ reduction to $\mathrm{CO}$ on $\{111\}$ and $\{112\}$ surfaces of $\mathrm{CO}_{3} \mathrm{O}_{4}$ hexagonal platelets. Reproduced with permission from ref. 77, copyright 2016 John Wiley and Sons. (b) Density of states (DOS) plots for $\{101\}$ and $\{001\}$ surfaces of anatase $\mathrm{TiO}_{2}$. (c) Illustration of $\{001\}$ and $\{101\}$ surface heterojunctions. Reproduced with permission from ref. 73, copyright 2014 American Chemical Society. (d and e) SEM images of $\mathrm{BiOlO}_{3}$ with various thickness. (h) A schematic illustration of the morphology evolution for $\mathrm{BiOlO}_{3}$ with various thicknesses. Reproduced with permission from ref. 78, copyright 2018 John Wiley and Sons. 
posed $\{101\}$ and $\{001\}$ facets within a single $\mathrm{TiO}_{2}$ particle, forming a "surface heterojunction" toward enhanced activity in the photocatalytic reduction of $\mathrm{CO}_{2}$ to $\mathrm{CH}_{4}{ }^{73}$ DFT calculations for the electronic structure (Fig. $9 \mathrm{~b}$ and c) reveal that the Fermi levels of $\{001\}$ facets and $\{101\}$ facets are hauled to equal due to their contact, forming facet heterojunctions to facilitate the transfer and separation of photogenerated electrons and holes. Similarly, Chen et al. have synthesized $\mathrm{BiOIO}_{3}$ nanoplates with an adjustable proportion of exposed $\{010\}$ top facets to $\{100\}$ lateral facets by altering the thickness. ${ }^{78}$ The decrease in thickness of $\mathrm{BiOIO}_{3}$ nanoplates tuned the ratio of $\{010\} /\{100\}$ facet junctions (Fig. 9d-h), which significantly shortened the diffusion pathway for charge carriers and allowed the efficient separation of photogenerated electrons and holes on the anisotropic facets. As a result, the activity for the photocatalytic reduction of $\mathrm{CO}_{2}$ to $\mathrm{CO}$ was greatly improved.

Overall, facet engineering is an effective strategy for selectively exposing catalytically active sites by modulating the atomic arrangement on surfaces, which has a great impact on molecular adsorption and desorption of intermediates. Furthermore, co-exposure of multi-facets allows efficient charger transfer and separation by spatially separating the photogenerated electrons and holes on the anisotropic facets.

\subsection{Heterogeneous single metal sites}

Generally in heterogeneous catalysts, high dispersion of the active sites results in good catalytic performance. In this regard, great efforts have been focused on highly dispersed catalysts with ultrasmall sizes, even at the atomic scale. Fabrication of isolated metal active sites plays an unprecedented role in governing the activity and selectivity of heterogeneous metal catalysts. ${ }^{15-17,79,80}$ As we have discussed in the section above, the highly efficient cocatalysts in photocatalytic $\mathrm{CO}_{2}$ reduction are commonly noble metals. To maximize the efficiency of each active site and minimize the cost, single-site catalysts are intriguing and have attracted widespread interest in photocatalytic $\mathrm{CO}_{2}$ reduction considering their merits of high atomic utilization and easy modification of both the spatial and electronic environment of active sites. To this end, a variety of single metal sites, including isolated ions, atoms, and molecular complexes, have been engineered on light-harvesting supports to explore their potential in photocatalytic $\mathrm{CO}_{2}$ reduction.

One goal for solar-driven $\mathrm{CO}_{2}$ conversion is to develop visible-light photocatalysts. Huang et al. have engineered single $\mathrm{Co}^{2+}$ sites on carbon nitride $\left(\mathrm{C}_{3} \mathrm{~N}_{4}\right)$ by a simple microwaveassistant deposition method, in which framework nitrogen atoms can coordinate with and activate $\mathrm{Co}^{2+}$ sites demonstrating excellent activity and selectivity toward visible-light photocatalytic $\mathrm{CO}_{2}$ reduction into $\mathrm{CO}{ }^{81}$ With the same cobalt loading, the amount of $\mathrm{CO}$ produced by single-site $\mathrm{Co}^{2+} @ \mathrm{C}_{3} \mathrm{~N}_{4}$ is almost 5 times higher than that produced by the mixture of $\mathrm{CoCl}_{2}$ and $\mathrm{C}_{3} \mathrm{~N}_{4}$, suggesting that single $\mathrm{Co}^{2+}$ site coordinated with $\mathrm{N}$ on $\mathrm{C}_{3} \mathrm{~N}_{4}$ could be activated to exhibit superior activity. Beyond semiconductors, Au nanoclusters (NCs) can serve as a potential light absorber to harvest visible light but are inert for photocatalytic $\mathrm{CO}_{2}$ reduction due to the lack of catalytic sites. In this regard, our research group has developed an effective strategy to graft various metal cations on Au NCs through bridging ligands. ${ }^{82}$ The grafted isolated metal cations $\left(\mathrm{Fe}^{2+}, \mathrm{Co}^{2+}\right.$, $\mathrm{Ni}^{2+}$, and $\mathrm{Cu}^{2+}$ ) can accept photogenerated electrons from $\mathrm{Au}$ NCs through the bridging ligands (L-cysteine) and serve as catalytic sites for $\mathrm{CO}_{2}$ reduction. Demonstrated by DFT calculations (Fig. 10), different single metal sites possess varied d-band centers and binding energies with $\mathrm{CO}_{2}$ molecules, which allow for tuning electron transfer efficiency and $\mathrm{CO}_{2}$ activation energy to control the activity and selectivity. This work provides an effective strategy for engineering single active sites on inert light-harvesting components through bridging ligands.

In addition to metal ions, various isolated single metal atoms also have been engineered on semiconductors for photocatalytic $\mathrm{CO}_{2}$ reduction, which enables the regulation of selectivity for high-valued hydrocarbon products such as methane. Our research group has designed highly selective active sites for the photocatalytic reduction of $\mathrm{CO}_{2}$ to $\mathrm{CH}_{4}$ via isolating $\mathrm{Cu}$ atom in the Pd lattice supported on a $\mathrm{TiO}_{2}$ semiconductor. ${ }^{80}$ The d-band centers of isolated $\mathrm{Cu}$ atoms were elevated through the electronic structure coupling with surrounding Pd atoms, which enhanced the adsorption and activation of $\mathrm{CO}_{2}$, as well as suppressed competing $\mathrm{H}_{2}$ evolution. As a result, the obtained photocatalyst exhibited a high selectivity of $96 \%$ for $\mathrm{CO}_{2}$ reduction to $\mathrm{CH}_{4}$, with a production rate of $19.6 \mu \mathrm{mol} \mathrm{g}_{\mathrm{cat}}{ }^{-1} \mathrm{~h}^{-1}$.

Compared with heterogeneous catalysts, the metal centers in homogeneous catalysts are well separated by organic ligands, which can serve as highly efficient single active sites. Engineering the active sites in homogeneous systems could be easily modulated through adjusting the metal centers with various linked organic ligands. Benefiting from the isolated catalytic sites and versatile coordination forms, homogeneous photocatalysts have shown excellent capacity in light absorption as well as high activity and selectivity for $\mathrm{CO}_{2}$ reduction. ${ }^{18,19,21,22,83-90}$ Considering that homogeneous and heterogeneous photocatalysts both have their own strengths and weaknesses, it is a promising strategy to combine together the merits of each. To this end, our research group has developed a highly efficient photocatalytic system for $\mathrm{CO}_{2}$ reduction by bridging the heterogeneous single-atom Co as an active site
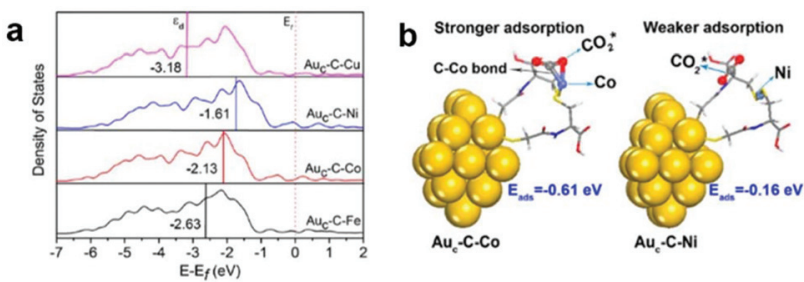

Fig. 10 (a) Projected density of states (PDOS) of the d-orbitals of surface atoms for $\mathrm{Au}_{\mathrm{c}}-\mathrm{C}-\mathrm{Fe}, \mathrm{Au}_{\mathrm{c}}-\mathrm{C}-\mathrm{Co}, \mathrm{Au}_{\mathrm{c}}-\mathrm{C}-\mathrm{Ni}$, and $\mathrm{Au}_{\mathrm{c}}-\mathrm{C}-\mathrm{Cu}$. (b) Models for $\mathrm{CO}_{2}$ adsorption on the $\mathrm{Au}_{\mathrm{c}}-\mathrm{C}-\mathrm{Co}$ surface (left) and $\mathrm{Au}_{\mathrm{c}}-\mathrm{C}-$ $\mathrm{Ni}$ surface (right). Reproduced with permission from ref. 82, copyright 2018 American Chemical Society. 
with a homogeneous light absorber $\left[\mathrm{Ru}(\mathrm{bpy})_{3}\right] \mathrm{Cl}_{2}$ through graphene. ${ }^{79}$ The individual and isolated Co atoms coordinated on the partially oxidized graphene nanosheets can be regarded as homogeneous catalyst analogues, which achieved an outstanding turnover number (TON) of 678 for $\mathrm{CO}$ production with an high turnover frequency (TOF) of $3.77 \mathrm{~min}^{-1}$. Inversely, metal molecular complexes also can be anchored on various semiconductor supports as heterogeneous single active sites. Such photocatalysts possess the merits of high TON and good durability provided by the homogeneous catalyst and heterogeneous catalyst, respectively. Kuriki et al. have designed a $\mathrm{Ru}$ complex anchored on $\mathrm{C}_{3} \mathrm{~N}_{4}$ as the catalytic sites for the photocatalytic reduction of $\mathrm{CO}_{2}$ into formic acid, achieving a high TON more than 1000 (by $20 \mathrm{~h}$ ) and an apparent quantum yield of $5.7 \%$ (under irradiation light of $\lambda=400 \mathrm{~nm}$ ). ${ }^{91}$ Considering the complicated preparation process of the $\mathrm{Ru}$ complex and the rarity of $\mathrm{Ru}$, Ye's group has designed a covalently linked hybrid photocatalyst composed of a non-noble metal based Co-porphyrin molecule catalyst and oligomers of melems (CoPOM) for photocatalytic $\mathrm{CO}_{2}$ reduction. ${ }^{92}$ The high affinity of Co active sites for $\mathrm{CO}_{2}$ and efficient electron trapping by the Co active sites contributed to the enhanced activity for $\mathrm{CO}_{2}$ reduction.

Overall, the engineering of atomically dispersed active sites in a heterogeneous catalysis system offers unique opportunities for combining the advantages of homogeneous and heterogeneous catalysis, thereby building a bridge between them. Single-atom photocatalysts exhibit high atomic utilization, low cost and high activity, which well meets the original intention for catalyst design. However, there still remain challenges in the fabrication of spatially uniform, highly dispersed and stable single-atom photocatalysts, due to that the extremely active metal single-atoms favourably aggregate or react with the surrounding reactants to form undesired species during fabrication and reaction. For this reason, seeking and developing novel strategies to controllably synthesize singleatom photocatalysts with a high metal content and robustness is of great significance to fully show their capability in practical application.

\subsection{Active sites in metal-organic frameworks}

Metal-organic frameworks (MOFs) are springing up as a new class of crystalline porous materials consisting of metal nodes and organic linkers. ${ }^{93}$ By functionalizing metal nodes and organic linkers to tailor their local environments, the physical and chemical properties of MOFs can be finely tuned, making them as promising materials for small molecule adsorption and conversion..$^{93,94}$ With regard to $\mathrm{CO}_{2}$ capture and conversion, MOFs can provide excellent active sites for adsorption and activation based on their unique advantages: (i) ultrahigh surface area and porous structure for gaseous uptake; (ii) diversiform metal centers and organic ligands for engineering active sites. ${ }^{1,95-97}$ Therefore, modulating different metal centers and organic linkers in MOFs provides an alternative strategy for engineering active sites toward photocatalytic $\mathrm{CO}_{2}$ reduction.
Open metal nodes in MOFs bridging with ligands can serve as isolated active sites for $\mathrm{CO}_{2}$ reduction. ${ }^{98}$ Wang et al. reported a series of Fe-containing MOFs (MIL-101(Fe), MIL-53 (Fe), MIL-88B(Fe)) for photocatalytic $\mathrm{CO}_{2}$ reduction to formate under visible light irradiation. ${ }^{99}$ Upon light irradiation, the electron transferred from $\mathrm{O}^{2-}$ to $\mathrm{Fe}^{3+}$ center to form $\mathrm{Fe}^{2+}$, and then the unsaturated coordination of Fe nodes endowed open active sites for $\mathrm{CO}_{2}$ adsorption and activation. Beyond metal nodes, another important component of MOFs, organic linkers, also show potential for engineering active sites for facilitating $\mathrm{CO}_{2}$ adsorption and activation. The aforementioned strategy of introducing Lewis base sites on surfaces also works for MOFs. Incorporation of organic linkers bearing Lewis base sites into MOFs has been proven to greatly improve their binding affinities for $\mathrm{CO}_{2}$. For instance, organic linkers having uncoordinated amine-containing functional groups in MOFs can provide the binding sites for $\mathrm{CO}_{2}$. Such binding sites nearby the metal active sites significantly enhance the efficiency for $\mathrm{CO}_{2}$ reduction. ${ }^{100,101} \mathrm{Fu}$ et al. have reported amine-functionalized titanium MOFs ( $\mathrm{NH}_{2}-\mathrm{MIL}-125$ (Ti)) for the photocatalytic reduction of $\mathrm{CO}_{2}$ to formic acid under visible light irradiation. ${ }^{100}$ The presence of the amino functional group enhanced the interaction with $\mathrm{CO}_{2}$ molecules and also extended light absorption from $350 \mathrm{~nm}$ (UV-responsive MIL-125(Ti)) to $550 \mathrm{~nm}\left(\mathrm{NH}_{2}\right.$-MIL-125(Ti)) (Fig. 11a). During light irradiation, the photogenerated electrons transfer from the organic ligand to the $\mathrm{Ti}^{4+}$ node in $\mathrm{NH}_{2}$-MIL-125(Ti) generating $\mathrm{Ti}^{3+}$, which is the active site for $\mathrm{CO}_{2}$ adsorption and reduction (Fig. 11b). Apart from amine-functionalized ligands, other nitrogen containing ligands including pyrimidines, azoles and triazines, could also be incorporated into MOFs as Lewis base sites for $\mathrm{CO}_{2}$ capture.

The active sites in MOFs are not limited to their own components. In addition to the original metal nodes and organic linkers in MOFs, the single sites or metal complexes introduced into the MOF structure could also serve as active sites, providing an alternative strategy to engineer active sites in MOFs for $\mathrm{CO}_{2}$ conversion. ${ }^{59,97,102-104}$ Lin and coworkers have reported the integration of different molecular complexes in UiO-67(Zr) for photocatalytic $\mathrm{CO}_{2}$ reduction under visible light irradiation. ${ }^{102}$ Beyond that, Yaghi' s group has simultaneously encapsulated Ag nanocube and Re molecular complexes into a zirconium MOF. ${ }^{104}$ Utilizing intensified near-surface electric

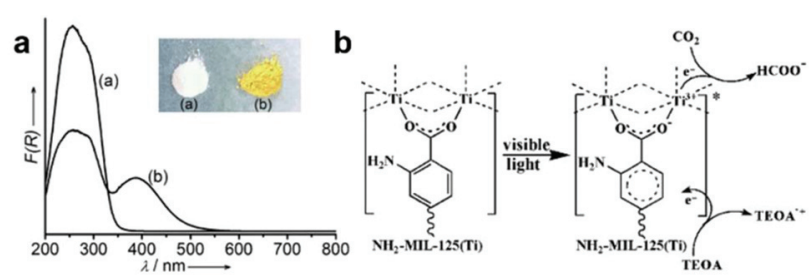

Fig. 11 (a) UV-vis spectra of MIL-125(Ti) and $\mathrm{NH}_{2}-\mathrm{MIL}-125(\mathrm{Ti})$. (b) Proposed mechanism of $\mathrm{CO}_{2}$ reduction over $\mathrm{NH}_{2}-\mathrm{MIL}-125(\mathrm{Ti})$ under visible light irradiation. Reproduced with permission from ref. 100, copyright 2012 John Wiley and Sons. 
fields at the surface of $\mathrm{Ag}$ nanocubes, the spatially confined photoactive Re centers resulted in a 7-fold improvement of $\mathrm{CO}_{2}$-to-CO conversion under visible light.

In brief, designing appropriate metal nodes and organic linkers, as well as incorporating additional functional moieties and metal sites into MOFs, opens up a promising method of engineering active sites for photocatalytic $\mathrm{CO}_{2}$ reduction. However, one main challenge to be resolved is that most of the MOFs suffer from inferior stability under long-time light irradiation in aqueous solutions. ${ }^{94}$

\section{Summary and outlook}

In this review, enormous achievements have been witnessed in the photocatalytic conversion of $\mathrm{CO}_{2}$ by taking advantage of engineering active sites (Table 2). Engineering active sites can dramatically improve catalytic activity, and regulate the reaction pathway achieving high selectivity for target products. The developed strategies for engineering active sites on surfaces and in open frameworks have been systematically summarized, including creating surface vacancies, doping heteroatoms, modifying functional groups, loading metal nanoparticles, engineering crystal facets, dispersing heterogeneous single-site catalysts, anchoring homogeneous single-site catalysts, and modulating metal nodes or organic linkers in MOFs. Whatever their existing forms are, the essential feature of engineering active sites is to tune the surface state and local electronic structure of the active sites, which significantly influences the adsorption and activation of the $\mathrm{CO}_{2}$ molecule, broadens light absorption and promotes photogenerated charge separation and transfer.

Although remarkable progress has been made in engineering active sites on surfaces and in open frameworks, there

Table 2 Comparison of various methods for engineering active sites toward photocatalytic $\mathrm{CO}_{2}$ reduction

\begin{tabular}{|c|c|c|c|c|c|}
\hline Method & & Catalyst & Products & Reaction conditions & Ref. \\
\hline & $\begin{array}{l}\text { Oxygen } \\
\text { vacancy }\end{array}$ & $\mathrm{Bi}_{2} \mathrm{WO}_{6}$ & $\mathrm{CH}_{4}, 13.94 \mu \mathrm{mol} \mathrm{g}^{-1}$ & $500 \mathrm{~W}$ Xe lamp & 34 \\
\hline & $\begin{array}{l}\text { Oxygen } \\
\text { vacancy }\end{array}$ & $\mathrm{Bi}_{12} \mathrm{O}_{17} \mathrm{Cl}_{2}$ & $\mathrm{CO}, 48.6 \mu \mathrm{mol} \mathrm{g}^{-1} \mathrm{~h}^{-1}$ & $\mathrm{H}_{2} \mathrm{O}, 300 \mathrm{~W}$ Xe lamp & 30 \\
\hline \multirow[t]{5}{*}{ Heteroatom doping } & Ni doping & $\mathrm{Ni}-\mathrm{ZnCo}_{2} \mathrm{O}_{4}$ & $\begin{array}{l}\mathrm{CO}, 31.4 \mu \mathrm{mol} \mathrm{g}^{-1} \mathrm{~h}^{-1} \\
\mathrm{CH}_{4}, 20.2 \mu \mathrm{mol} \mathrm{g}^{-1} \mathrm{~h}^{-1}\end{array}$ & $\mathrm{H}_{2} \mathrm{O}, 300 \mathrm{~W}$ Xe lamp (AM 1.5 filter) & 38 \\
\hline & Ni doping & ${ }^{b} \mathrm{Ni}: \mathrm{CdS}$ QDs & $\begin{array}{l}\mathrm{CO}, \sim 9 \mu \mathrm{mol} \mathrm{g}^{-1} \mathrm{~h}^{-1} \\
\mathrm{CH}_{4}, \sim 1 \mu \mathrm{mol} \mathrm{g}^{-1} \mathrm{~h}^{-1}\end{array}$ & $\mathrm{H}_{2} \mathrm{O},{ }^{c}$ TEOA, $300 \mathrm{~W}$ Xe lamp $(\lambda \geq 400 \mathrm{~nm})$ & 39 \\
\hline & Co doping & $\mathrm{Co}_{-\mathrm{BiVO}_{4}}$ & $\mathrm{CH}_{4}, 3.57 \mu \mathrm{mol}(4 \mathrm{~h})$ & $\mathrm{H}_{2} \mathrm{O}, 25 \mathrm{~W}$ ultraviolet lamp $(\lambda=284 \mathrm{~nm})$ & 37 \\
\hline & B doping & B- $\mathrm{C}_{3} \mathrm{~N}_{4}$ & $\mathrm{CH}_{4}, 0.16 \mu \mathrm{mol} \mathrm{g}^{-1} \mathrm{~h}^{-1}$ & $300 \mathrm{~W}$ Xe lamp & 45 \\
\hline & I doping & $\mathrm{I}-\mathrm{TiO}_{2}$ & $\mathrm{CO}, 2.4 \mu \mathrm{mol} \mathrm{g}^{-1} \mathrm{~h}^{-1}$ & $\mathrm{H}_{2} \mathrm{O}$ vapor, $450 \mathrm{~W}$ Xe lamp $(\lambda \geq 400 \mathrm{~nm})$ & 48 \\
\hline cocatalyst & $\mathrm{AuAg}$ & $\mathrm{AuAg}-\mathrm{TiO}_{2}$ & $\begin{array}{l}\mathrm{CO}, 1813 \mu \mathrm{mol} \mathrm{g}^{-1} \mathrm{~h}^{-1} \\
\mathrm{CH}_{4}, 35 \mu \mathrm{mol} \mathrm{g}^{-1} \mathrm{~h}^{-1}\end{array}$ & $200 \mathrm{~W} \mathrm{Hg}$ lamp & 68 \\
\hline & $\mathrm{AuCu}$ & $\mathrm{Au}_{3} \mathrm{Cu} @ \mathrm{SrTiO}_{3} / \mathrm{TiO}_{2}$ & $\mathrm{CH}_{4}, 421.2 \mu \mathrm{mol} \mathrm{g}^{-1} \mathrm{~h}^{-1}$ & $\mathrm{~N}_{2} \mathrm{H}_{4} \cdot \mathrm{H}_{2} \mathrm{O}, 300 \mathrm{~W}$ Xe lamp & 67 \\
\hline & $\mathrm{PdH}_{0.43}$ & $\mathrm{PdH}_{0.43}-\mathrm{TiO}_{2}$ & $\mathrm{CH}_{4}, 82.4 \mu \mathrm{mol} \mathrm{g}^{-1}(4 \mathrm{~h})$ & $\mathrm{H}_{2} \mathrm{O}, 300 \mathrm{~W}$ Xe lamp & 27 \\
\hline \multirow[t]{4}{*}{ Facet engineering } & $\{112\}$ & $\mathrm{Co}_{3} \mathrm{O}_{4}\{112\}$ & $\mathrm{CO}, 2003 \mu \mathrm{mol} \mathrm{g}{ }^{-1} \mathrm{~h}^{-1}$ & $\begin{array}{l}{\left[\mathrm{Ru}(\mathrm{bpy})_{3}\right] \mathrm{Cl}_{2},{ }^{d} \mathrm{MeCN}, \mathrm{TEOA}, \mathrm{H}_{2} \mathrm{O}} \\
300 \mathrm{~W} \text { Xe lamp }(\lambda>420 \mathrm{~nm})\end{array}$ & 77 \\
\hline & $\{111\}$ & $\operatorname{Pd}\{111\}-\mathrm{C}_{3} \mathrm{~N}_{4}$ & $\mathrm{CH}_{3} \mathrm{OH}, 3.17 \mu \mathrm{mol} \mathrm{g}^{-1} \mathrm{~h}^{-1}$ & $\mathrm{NaHCO}_{3}, \mathrm{H}_{2} \mathrm{SO}_{4}(2 \mathrm{M}), 300 \mathrm{~W}$ Xe lamp & 76 \\
\hline & $\{101\} /\{001\}$ & $\mathrm{TiO}_{2}\{101\} /\{001\}$ & $\mathrm{CH}_{4}, 1.35 \mu \mathrm{mol} \mathrm{g}^{-1} \mathrm{~h}^{-1}$ & $\mathrm{NaHCO}_{3}, \mathrm{HCl}(4 \mathrm{M}), 300 \mathrm{~W}$ Xe lamp & 73 \\
\hline & $(730)$ & $\mathrm{PtCu}(730)-\mathrm{C}_{3} \mathrm{~N}_{4}$ & $\begin{array}{l}\mathrm{CO}, 0.046 \mu \mathrm{mol} \mathrm{h}^{-1} \\
\mathrm{CH}_{4}, 0.112 \mu \mathrm{mol} \mathrm{h}^{-1}\end{array}$ & $\mathrm{H}_{2} \mathrm{O}, 300 \mathrm{~W}$ Xe lamp $(780 \mathrm{~nm}-400 \mathrm{~nm})$ & 75 \\
\hline \multirow[t]{3}{*}{ Single metal site } & Co & $\mathrm{Co}_{1}$-graphene & CO, TON 678TOF, $3.77 \mathrm{~min}^{-1}$ & $\begin{array}{l}{\left[\mathrm{Ru}(\mathrm{bpy})_{3}\right] \mathrm{Cl}_{2}, \mathrm{MeCN}, \text { TEOA, } \mathrm{H}_{2} \mathrm{O},} \\
300 \text { We lamp }(\lambda \geq 400 \mathrm{~nm})\end{array}$ & 79 \\
\hline & $\mathrm{Au}$ & ${ }^{e} \mathrm{Au}-\mathrm{GSH}$ NCs & $\mathrm{CO}, 3.45 \mu \mathrm{mol} \mathrm{g}^{-1} \mathrm{~h}^{-1}$ & TEOA, $300 \mathrm{~W}$ Xe lamp $(\lambda \geq 420 \mathrm{~nm})$ & 82 \\
\hline & $\mathrm{Cu}$ & $\mathrm{Pd}_{7} \mathrm{Cu}_{1}-\mathrm{TiO}_{2}$ & $\mathrm{CH}_{4}, 19.6 \mu \mathrm{mol} \mathrm{g}^{-1} \mathrm{~h}^{-1}$ & $300 \mathrm{~W}$ Xe lamp $(\lambda \geq 400 \mathrm{~nm})$ & 80 \\
\hline
\end{tabular}

${ }^{a}$ LDH: layered double hydroxides; ${ }^{b}$ QDs: quantum dots; ${ }^{c}$ TEOA: triethanolamine; ${ }^{d}$ MeCN: acetonitrile; ${ }^{e}$ Au-GSH NCs: glutathione-protected Au nanoclusters. 
remain grand challenges and several issues that should be taken into consideration. Firstly, these photocatalysts are far from being put to practical use. The development of photocatalysts with broad-spectrum light absorption is in high demand to enhance the efficiency of light utilization as the UV region only accounts for a limited portion (5\%) of natural sunlight. Thus continuous research efforts should be devoted to increase the efficiency of photocatalytic $\mathrm{CO}_{2}$ reduction by taking advantage of engineering active sites and efficiently cooperating with broad-spectrum light-harvesting units. Secondly, the bottlenecks of $\mathrm{CO}_{2}$ reduction are the competing $\mathrm{H}_{2}$ evolution and the limited selectivity toward certain products. Meanwhile, the major carbon products from photocatalytic $\mathrm{CO}_{2}$ reduction are mono-carbon products, while energy-rich multi-carbon products are greatly pursued. In this regard, the local electronic structure of the active sites should be further finely tuned to achieve real artificial photosynthesis. Thirdly, the structure-performance relationship remains ambiguous thus far. For this reason, advanced in situ characterization techniques should be applied to resolve the detailed structure and catalytic process during photocatalytic reactions, which would provide instructional guidance for designing and constructing active sites. Inspired by multidisciplinary cooperation, integrating active sites at the atomic level and resolving the underlying mechanisms at the atom/molecular level will pave the way for identifying efficient catalytic systems.

\section{Conflicts of interest}

There are no conflicts to declare.

\section{Acknowledgements}

This work was supported by the National Key R\&D Program of China (2017YFA0207301), NSFC (21725102, 91961106, 91963108, and 21703220), CAS Key Research Program of Frontier Sciences (QYZDB-SSW-SLH018), and CAS Interdisciplinary Innovation Team, DNL Cooperation Fund, CAS (DNL201922).

\section{Notes and references}

1 X. Chang, T. Wang and J. Gong, Energy Environ. Sci., 2016, 9, 2177-2196.

2 T. Inoue, A. Fujishima, S. Konishi and K. Honda, Nature, 1979, 277, 637.

3 S. Bai, J. Jiang, Q. Zhang and Y. Xiong, Chem. Soc. Rev., 2015, 44, 2893-2939.

4 Z. Chen, H. Zhang, P. Guo, J. Zhang, G. Tira, Y. J. Kim, Y. A. Wu, Y. Liu, J. Wen, T. Rajh, J. Niklas, O. G. Poluektov, P. D. Laible and E. A. Rozhkova, J. Am. Chem. Soc., 2019, 141, 11811-11815.
5 X. Li, J. Yu, M. Jaroniec and X. Chen, Chem. Rev., 2019, 119, 3962-4179.

6 S. Bai, W. Yin, L. Wang, Z. Li and Y. Xiong, RSC Adv., 2016, 6, 57446-57463.

7 K. Li, B. Peng and T. Peng, ACS Catal., 2016, 6, 74857527.

8 S. Bai, L. Wang, Z. Li and Y. Xiong, Adv. Sci., 2017, 4, 1600216.

9 C. Gao, J. Wang, H. Xu and Y. Xiong, Chem. Soc. Rev., 2017, 46, 2799-2823.

10 Y. Zhao, G. Chen, T. Bian, C. Zhou, G. I. N. Waterhouse, L.-Z. Wu, C.-H. Tung, L. J. Smith, D. O'Hare and T. Zhang, Adv. Mater., 2015, 27, 7824-7831.

11 J. Wu, M. Liu, P. P. Sharma, R. M. Yadav, L. Ma, Y. Yang, X. Zou, X.-D. Zhou, R. Vajtai, B. I. Yakobson, J. Lou and P. M. Ajayan, Nano Lett., 2016, 16, 466-470.

12 L. Liu, F. Gao, H. Zhao and Y. Li, Appl. Catal., B, 2013, 134-135, 349-358.

13 W. Deng, L. Zhang, L. Li, S. Chen, C. Hu, Z.-J. Zhao, T. Wang and J. Gong, J. Am. Chem. Soc., 2019, 141, 29112915.

14 Z. He, J. Tang, J. Shen, J. Chen and S. Song, Appl. Surf. Sci., 2016, 364, 416-427.

15 G. Gao, Y. Jiao, E. R. Waclawik and A. Du, J. Am. Chem. Soc., 2016, 138, 6292-6297.

16 Y. Guo, S. Mei, K. Yuan, D.-J. Wang, H.-C. Liu, C.-H. Yan and Y.-W. Zhang, ACS Catal., 2018, 8, 6203-6215.

17 J. C. Matsubu, V. N. Yang and P. Christopher, J. Am. Chem. Soc., 2015, 137, 3076-3084.

18 J. Bonin, M. Robert and M. Routier, J. Am. Chem. Soc., 2014, 136, 16768-16771.

19 S. Sato, T. Morikawa, T. Kajino and O. Ishitani, Angew. Chem., Int. Ed., 2013, 52, 988-992.

20 A. Nakada, R. Kuriki, K. Sekizawa, S. Nishioka, J. J. M. Vequizo, T. Uchiyama, N. Kawakami, D. Lu, A. Yamakata, Y. Uchimoto, O. Ishitani and K. Maeda, ACS Catal., 2018, 8, 9744-9754.

21 T. Ouyang, H.-H. Huang, J.-W. Wang, D.-C. Zhong and T.-B. Lu, Angew. Chem., Int. Ed., 2017, 56, 738-743.

$22 \mathrm{H}$. Takeda, K. Koike, H. Inoue and O. Ishitani, J. Am. Chem. Soc., 2008, 130, 2023-2031.

23 X. Liu, S. Inagaki and J. Gong, Angew. Chem., Int. Ed., 2016, 55, 14924-14950.

24 C. Y. Toe, J. Scott, R. Amal and Y. H. Ng, J. Photochem. Photobiol., C, 2019, 40, 191-211.

25 C. Y. Toe, Z. Zheng, H. Wu, J. Scott, R. Amal and Y. H. Ng, Angew. Chem., Int. Ed., 2018, 57, 13613-13617.

26 S. N. Habisreutinger, L. Schmidt-Mende and J. K. Stolarczyk, Angew. Chem., Int. Ed., 2013, 52, 73727408.

27 Y. Zhu, C. Gao, S. Bai, S. Chen, R. Long, L. Song, Z. Li and Y. Xiong, Nano Res., 2017, 10, 3396-3406.

28 S. Bai, N. Zhang, C. Gao and Y. Xiong, Nano Energy, 2018, 53, 296-336.

29 Y. Wang, P. Han, X. Lv, L. Zhang and G. Zheng, Joule, 2018, 2, 2551-2582. 
30 J. Di, C. Zhu, M. Ji, M. Duan, R. Long, C. Yan, K. Gu, J. Xiong, Y. She, J. Xia, H. Li and Z. Liu, Angew. Chem., Int. Ed., 2018, 57, 14847-14851.

31 L. Zhang, W. Wang, D. Jiang, E. Gao and S. Sun, Nano Res., 2015, 8, 821-831.

32 H. Yu, J. Li, Y. Zhang, S. Yang, K. Han, F. Dong, T. Ma and H. Huang, Angew. Chem., Int. Ed., 2019, 58, 3880-3884.

33 J. Lee, D. C. Sorescu and X. Deng, J. Am. Chem. Soc., 2011, 133, 10066-10069.

34 X. Y. Kong, Y. Y. Choo, S.-P. Chai, A. K. Soh and A. R. Mohamed, Chem. Commun., 2016, 52, 14242-14245.

35 X. Jiao, Z. Chen, X. Li, Y. Sun, S. Gao, W. Yan, C. Wang, Q. Zhang, Y. Lin, Y. Luo and Y. Xie, J. Am. Chem. Soc., 2017, 139, 7586-7594.

36 Y. Wang, F. Wang, Y. Chen, D. Zhang, B. Li, S. Kang, X. Li and L. Cui, Appl. Catal., B, 2014, 147, 602-609.

37 K. Wang, L. Zhang, Y. Su, S. Sun, Q. Wang, H. Wang and W. Wang, Catal. Sci. Technol., 2018, 8, 3115-3122.

38 K. Liu, X. Li, L. Liang, J. Wu, X. Jiao, J. Xu, Y. Sun and Y. Xie, Nano Res., 2018, 11, 2897-2908.

39 J. Wang, T. Xia, L. Wang, X. Zheng, Z. Qi, C. Gao, J. Zhu, Z. Li, H. Xu and Y. Xiong, Angew. Chem., Int. Ed., 2018, 57, 16447-16451.

40 Slamet, H. W. Nasution, E. Purnama, S. Kosela and J. Gunlazuardi, Catal. Commun., 2005, 6, 313-319.

41 M. Tahir and N. S. Amin, Appl. Catal., B, 2015, 162, 98109.

42 L. Li, P. Li, Y. Wang, L. Lin, A. H. Shah and T. He, Appl. Surf. Sci., 2018, 452, 498-506.

43 K. Wang, Q. Li, B. Liu, B. Cheng, W. Ho and J. Yu, Appl. Catal., B, 2015, 176-177, 44-52.

44 B. Liu, L. Ye, R. Wang, J. Yang, Y. Zhang, R. Guan, L. Tian and X. Chen, ACS Appl. Mater. Interfaces, 2018, 10, 40014009.

45 J. Fu, K. Liu, K. Jiang, H. Li, P. An, W. Li, N. Zhang, H. Li, X. Xu, H. Zhou, D. Tang, X. Wang, X. Qiu and M. Liu, Adv. Sci., 2019, 6, 1900796.

46 J. W. F. To, J. He, J. Mei, R. Haghpanah, Z. Chen, T. Kurosawa, S. Chen, W.-G. Bae, L. Pan, J. B. H. Tok, J. Wilcox and Z. Bao, J. Am. Chem. Soc., 2016, 138, 10011009.

47 M. Xing, Y. Zhou, C. Dong, L. Cai, L. Zeng, B. Shen, L. Pan, C. Dong, Y. Chai, J. Zhang and Y. Yin, Nano Lett., 2018, 18, 3384-3390.

48 Q. Zhang, Y. Li, E. A. Ackerman, M. GajdardziskaJosifovska and H. Li, Appl. Catal., A, 2011, 400, 195-202.

49 Y. Li, C. Gao, R. Long and Y. Xiong, Mater. Today Chem., 2019, 11, 197-216.

50 I. Shown, S. Samireddi, Y. C. Chang, R. Putikam, P. H. Chang, A. Sabbah, F. Y. Fu, W. F. Chen, C. I. Wu, T. Y. Yu, P. W. Chung, M. C. Lin, L. C. Chen and K. H. Chen, Nat. Commun., 2018, 9, 169.

51 X. Pan, M.-Q. Yang, X. Fu, N. Zhang and Y.-J. Xu, Nanoscale, 2013, 5, 3601-3614.

52 D. Cornu, H. Guesmi, J.-M. Krafft and H. Lauron-Pernot, J. Phys. Chem. C, 2012, 116, 6645-6654.
53 H. Yu, S. Yan, P. Zhou and Z. Zou, Appl. Surf. Sci., 2018, 427, 603-607.

54 S. Xie, Y. Wang, Q. Zhang, W. Deng and Y. Wang, ACS Catal., 2014, 4, 3644-3653.

55 X. Meng, S. Ouyang, T. Kako, P. Li, Q. Yu, T. Wang and J. Ye, Chem. Commun., 2014, 50, 11517-11519.

56 D. Sun, Y. Fu, W. Liu, L. Ye, D. Wang, L. Yang, X. Fu and Z. Li, Chem. - Eur. J., 2013, 19, 14279-14285.

57 M. Ghoussoub, S. Yadav, K. K. Ghuman, G. A. Ozin and C. V. Singh, ACS Catal., 2016, 6, 7109-7117.

58 K. K. Ghuman, L. B. Hoch, P. Szymanski, J. Y. Y. Loh, N. P. Kherani, M. A. El-Sayed, G. A. Ozin and C. V. Singh, J. Am. Chem. Soc., 2016, 138, 1206-1214.

59 J. Ye and J. K. Johnson, ACS Catal., 2015, 5, 2921-2928.

60 W. Ye, R. Long, H. Huang and Y. Xiong, J. Mater. Chem. C, 2017, 5, 1008-1021.

61 D. Liu, Y. Fernández, O. Ola, S. Mackintosh, M. MarotoValer, C. M. A. Parlett, A. F. Lee and J. C. S. Wu, Catal. Commun., 2012, 25, 78-82.

62 I. Shown, H.-C. Hsu, Y.-C. Chang, C.-H. Lin, P. K. Roy, A. Ganguly, C.-H. Wang, J.-K. Chang, C.-I. Wu, L.-C. Chen and K.-H. Chen, Nano Lett., 2014, 14, 6097-6103.

63 M. Tasbihi, M. Schwarze, M. Edelmannová, C. Spöri, P. Strasser and R. Schomäcker, Catal. Today, 2019, 328, 814.

64 M. Anpo, H. Yamashita, Y. Ichihashi, Y. Fujii and M. Honda, J. Phys. Chem. B, 1997, 101, 2632-2636.

65 J. Ran, M. Jaroniec and S. Z. Qiao, Adv. Mater., 2018, 30, 1704649.

66 Y. Wang, Q. Lai, F. Zhang, X. Shen, M. Fan, Y. He and S. Ren, RSC Adv., 2014, 4, 44442-44451.

67 Q. Kang, T. Wang, P. Li, L. Liu, K. Chang, M. Li and J. Ye, Angew. Chem., Int. Ed., 2015, 54, 841-845.

68 M. Tahir, B. Tahir and N. A. S. Amin, Appl. Catal., B, 2017, 204, 548-560.

69 H. Wu, H. L. Tan, C. Y. Toe, J. Scott, L. Wang, R. Amal and Y. H. Ng, Adv. Mater., 2019, 1904717.

70 M. G. Kibria, S. Zhao, F. A. Chowdhury, Q. Wang, H. P. Nguyen, M. L. Trudeau, H. Guo and Z. Mi, Nat. Commun., 2014, 5, 3825.

71 H. L. Tan, F. F. Abdi and Y. H. Ng, Chem. Soc. Rev., 2019, 48, 1255-1271.

72 S. Bai, C. Gao, J. Low and Y. Xiong, Nano Res., 2018, 12, 2031-2054.

73 J. Yu, J. Low, W. Xiao, P. Zhou and M. Jaroniec, J. Am. Chem. Soc., 2014, 136, 8839-8842.

74 H. L. Tan, X. Wen, R. Amal and Y. H. Ng, J. Phys. Chem. Lett., 2016, 7, 1400-1405.

75 Q. Lang, Y. Yang, Y. Zhu, W. Hu, W. Jiang, S. Zhong, P. Gong, B. Teng, L. Zhao and S. Bai, J. Mater. Chem. A, 2017, 5, 6686-6694.

76 S. Cao, Y. Li, B. Zhu, M. Jaroniec and J. Yu, J. Catal., 2017, 349, 208-217.

77 C. Gao, Q. Meng, K. Zhao, H. Yin, D. Wang, J. Guo, S. Zhao, L. Chang, M. He, Q. Li, H. Zhao, X. Huang, Y. Gao and Z. Tang, Adv. Mater., 2016, 28, 6485-6490. 
78 F. Chen, H. Huang, L. Ye, T. Zhang, Y. Zhang, X. Han and T. Ma, Adv. Funct. Mater., 2018, 28, 1804284.

79 C. Gao, S. Chen, Y. Wang, J. Wang, X. Zheng, J. Zhu, L. Song, W. Zhang and Y. Xiong, Adv. Mater., 2018, 30, 1704624.

80 R. Long, Y. Li, Y. Liu, S. Chen, X. Zheng, C. Gao, C. He, N. Chen, Z. Qi, L. Song, J. Jiang, J. Zhu and Y. Xiong, J. Am. Chem. Soc., 2017, 139, 4486-4492.

81 P. Huang, J. Huang, S. A. Pantovich, A. D. Carl, T. G. Fenton, C. A. Caputo, R. L. Grimm, A. I. Frenkel and G. Li, J. Am. Chem. Soc., 2018, 140, 16042-16047.

82 X. Cui, J. Wang, B. Liu, S. Ling, R. Long and Y. Xiong, J. Am. Chem. Soc., 2018, 140, 16514-16520.

83 J. D. Froehlich and C. P. Kubiak, J. Am. Chem. Soc., 2015, 137, 3565-3573.

84 D. Hong, Y. Tsukakoshi, H. Kotani, T. Ishizuka and T. Kojima, J. Am. Chem. Soc., 2017, 139, 6538-6541.

85 T. Fogeron, P. Retailleau, L. M. Chamoreau, Y. Li and M. Fontecave, Angew. Chem., Int. Ed., 2018, 57, 17033-17037.

86 Z. Guo, S. Cheng, C. Cometto, E. Anxolabéhère-Mallart, S.-M. Ng, C.-C. Ko, G. Liu, L. Chen, M. Robert and T.-C. Lau, J. Am. Chem. Soc., 2016, 138, 9413-9416.

87 R. Kuriki, M. Yamamoto, K. Higuchi, Y. Yamamoto, M. Akatsuka, D. Lu, S. Yagi, T. Yoshida, O. Ishitani and K. Maeda, Angew. Chem., Int. Ed., 2017, 56, 4867-4871.

88 D. S. Laitar, P. Müller and J. P. Sadighi, J. Am. Chem. Soc., 2005, 127, 17196-17197.

89 C.-H. Lim, A. M. Holder and C. B. Musgrave, J. Am. Chem. Soc., 2013, 135, 142-154.

90 C. Liu, T. R. Cundari and A. K. Wilson, J. Phys. Chem. C, 2012, 116, 5681-5688.

91 R. Kuriki, K. Sekizawa, O. Ishitani and K. Maeda, Angew. Chem., Int. Ed., 2015, 54, 2406-2409.
92 G. Zhao, H. Pang, G. Liu, P. Li, H. Liu, H. Zhang, L. Shi and J. Ye, Appl. Catal., B, 2017, 200, 141-149.

93 M. Ding, R. W. Flaig, H. L. Jiang and O. M. Yaghi, Chem. Soc. Rev., 2019, 48, 2783-2828.

94 T. Zhang and W. Lin, Chem. Soc. Rev., 2014, 43, 59825993.

95 R. W. Flaig, T. M. O. Popp, A. M. Fracaroli, E. A. Kapustin, M. J. Kalmutzki, R. M. Altamimi, F. Fathieh, J. A. Reimer and O. M. Yaghi, J. Am. Chem. Soc., 2017, 139, 1212512128.

96 J. Wang, T. Xia, L. Wang, X. Zheng, Z. Qi, C. Gao, J. Zhu, Z. Li, H. Xu and Y. Xiong, Angew. Chem., Int. Ed., 2018, 57, 16447-16451.

97 Z. Liang, C. Qu, D. Xia, R. Zou and Q. Xu, Angew. Chem., Int. Ed., 2018, 57, 9604-9633.

98 C. S. Diercks, Y. Liu, K. E. Cordova and O. M. Yaghi, Nat. Mater., 2018, 17, 301-307.

99 D. Wang, R. Huang, W. Liu, D. Sun and Z. Li, ACS Catal., 2014, 4, 4254-4260.

100 Y. Fu, D. Sun, Y. Chen, R. Huang, Z. Ding, X. Fu and Z. Li, Angew. Chem., Int. Ed., 2012, 51, 3364-3367.

101 M. Anpo, H. Yamashita, K. Ikeue, Y. Fujii, S. G. Zhang, Y. Ichihashi, D. R. Park, Y. Suzuki, K. Koyano and T. Tatsumi, Catal. Today, 1998, 44, 327-332.

102 C. Wang, Z. Xie, K. E. deKrafft and W. Lin, J. Am. Chem. Soc., 2011, 133, 13445-13454.

103 H. Zhang, J. Wei, J. Dong, G. Liu, L. Shi, P. An, G. Zhao, J. Kong, X. Wang, X. Meng, J. Zhang and J. Ye, Angew. Chem., Int. Ed., 2016, 55, 14310-14314.

104 K. M. Choi, D. Kim, B. Rungtaweevoranit, C. A. Trickett, J. T. Barmanbek, A. S. Alshammari, P. Yang and O. M. Yaghi, J. Am. Chem. Soc., 2017, 139, 356-362. 